\title{
Perceptions of Risk in Intimacy: Couple Communication and Relationship Satisfaction
}

Amy Beth Brunell

College of William \& Mary - Arts \& Sciences

Follow this and additional works at: https://scholarworks.wm.edu/etd

Part of the Communication Commons, and the Social Psychology Commons

\section{Recommended Citation}

Brunell, Amy Beth, "Perceptions of Risk in Intimacy: Couple Communication and Relationship Satisfaction" (2002). Dissertations, Theses, and Masters Projects. Paper 1539626379.

https://dx.doi.org/doi:10.21220/s2-0etv-ve62

This Thesis is brought to you for free and open access by the Theses, Dissertations, \& Master Projects at W\&M ScholarWorks. It has been accepted for inclusion in Dissertations, Theses, and Masters Projects by an authorized administrator of W\&M ScholarWorks. For more information, please contact scholarworks@wm.edu. 


\title{
PERCEPTIONS OF RISK IN INTIMACY:
}

\section{COUPLE COMMUNICATION AND RELATIONSHIP SATISFACTION}

\section{A Thesis}

\section{Presented to}

The Faculty of the Department of Psychology

The College of William \& Mary in Virginia

\author{
In Partial Fulfillment \\ Of the Requirements for the Degree of \\ Master of Arts
}

by

Amy B. Brunell

2002 
APPROVAL SHEET

This thesis is submitted in partial fulfillment of the requirements for the degree of

Master of Arts

$\frac{\text { Amy B Bumell }}{\text { amy B. Brunel }}$

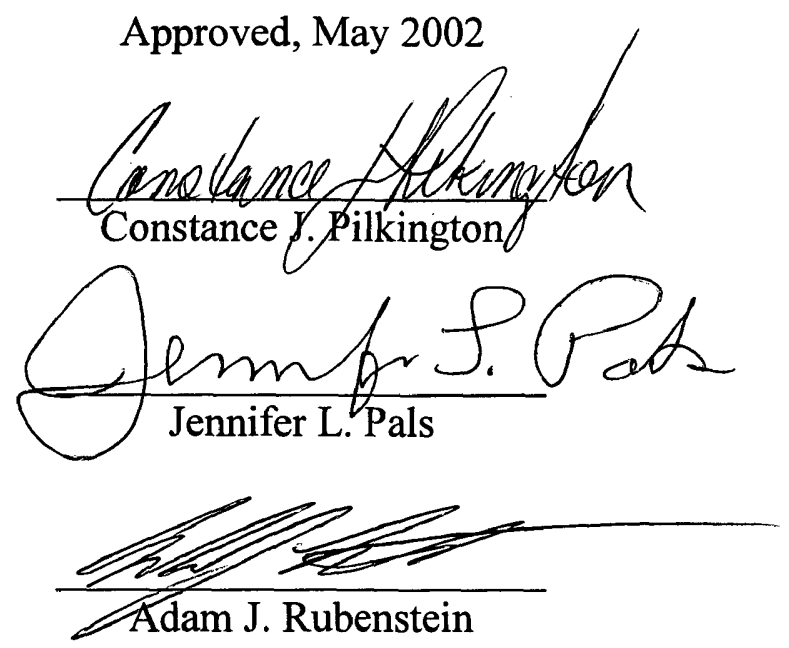

ii 


\section{DEDICATION}

To Kenny, for all his love and support. 


\section{TABLE OF CONTENTS}

Page

ACKNOWLEDGEMENTS

$\mathrm{V}$

LIST OF TABLES

vi

LIST OF FIGURES

vii

ABSTRACT

viii

INTRODUCTION

2

REFERENCES

48

APPENDIX A

67

APPENDIX B

68

APPENDIX C

70

APPENDIX D

71

APPENDIX E

73 


\section{ACKNOWLEDGEMENTS}

The author would like to express her appreciation to her advisor, Dr. Constance J. Pilkington, for her wisdom and guidance throughout this project and over the past two years. The author is indebted to her for all her encouragement and support.

The author would also like to thank the rest of her committee members, Dr. Adam Rubenstein and Dr. Jennifer Pals, for their careful reading and feedback on this thesis.

The author also recognizes her research assistant, Philip Kray. Without Philip, the author would still be collecting data! The author would also like to express her appreciation to Philip for always doing what he could to help and for providing comments on earlier drafts of this thesis.

Finally, the author would like to thank Antoinette Marty and John Simanski for taking the time and energy to code the videotapes. The coding was essential for the analysis of this study, and the author is indebted to them for adding this workload to their already busy schedules. 


\section{LIST OF TABLES}

Table

Page

1a. Pairwise Correlations for A's RII, Coders' Ratings of A's and B's Depth, A's Perception of B's Warmth, and Relationship Satisfaction.

1b. Pairwise Correlations for A's RII, Coders' Ratings of A's and B's Depth, A's Perception of B's Warmth, and Relationship Satisfaction.

1c. Pairwise Correlations for A's RII, A's Perception of B's Depth, B's Perception of A's Depth, A's Perception of B's Warmth, and Relationship Satisfaction.

2. Pairwise Correlations with A's Emotional Self-Disclosure 


\section{LIST OF FIGURES}

Figure

Page

Triangulation of A's Behavior.

Evaluation of A's RII and A's Intimate Behavior. $\quad 60$

3a. Proposed Model for A's RII, Coders' Ratings of A's and B's Depth, A's 61 Perception of B's Warmth, and Relationship Satisfaction.

3b. Proposed Model for A's RII, A's and B's Reported Depth, A's Report of B's Warmth, and Relationship Satisfaction.

3c. Proposed Model for A's RII, A's Perception of B's Depth, B's Perception of A's Depth, A's Perception of B's Warmth, and Relationship Satisfaction.

4. Proposed Model for A's RII, A's Self-Reported Depth, A's Emotional Self64 Disclosure, and Relationship Satisfaction.

5a. Proposed Model for A's RII, A's Emotional Self-Disclosure, A's Trust, 65 and Relationship Satisfaction.

5b. Proposed Model for A's RII, A's and B's Emotional Self-Disclosure, A's 66 and B's Trust, and Relationship Satisfaction. 


\begin{abstract}
Intimate disclosure is an important component of satisfaction in a romantic relationship. In the present study, it was proposed that the higher one's perception of risk in intimacy, the less intimate one would be in the relationship, the less trusting one would be of one's partner, and the less satisfied one would be in the relationship. 64 heterosexual couples discussed topics of a personal nature in the laboratory. These conversations were rated for depth by 2 coders who were blind to the participants' score on the Risk in Intimacy Inventory (RII; Pilkington \& Richardson, 1988). Participants also completed the Emotional Self-Disclosure Scale (ESDS; Snell, Miller, \& Belk, 1988), the Interpersonal Trust Scale (ITS; Rempel, Holmes, \& Zanna, 1985), and a measure of relationship satisfaction. It was found that those who scored higher on the RII were not rated by coders as being less intimate than those who scored lower on the RII. However, high-RII people perceived themselves and their partners as being less intimate in the conversation, reported being less trusting of their partners, and were less satisfied in the relationship than were low-RII individuals. Reasons for these findings are discussed.
\end{abstract}


PERCEPTIONS OF RISK IN INTIMACY:

COUPLE COMMUNICATION AND RELATIONSHIP SATISFACTION 


\section{INTRODUCTION}

People's ability to develop and maintain intimate relationships has been found to be a factor for adjustment and psychological well-being (e.g., McAdams \& Vaillant, 1982; Miller \& Lefcourt, 1982; Reis \& Shaver, 1988). For example, the inability to develop close, confiding relationships has been linked to depression in women, and the ability to establish and maintain intimate adult relationships is a key factor in adult male psychological health (Waring, 1981). Research on intimacy has demonstrated that people have an emotional need to feel close to others (see Baumeister \& Leary, 1995, for a review). According to Baumeister and Leary (1995), "the belongingness hypothesis is that human beings have a pervasive drive to form and maintain at least a minimum quantity of lasting, positive, and significant interpersonal relationships" (p. 497). In fact, the need to belong appears to have strong effects on both emotional and cognitive processes, and feeling that one does not belong has been linked to poorer health, adjustment, and well-being (Baumeister \& Leary, 1995).

\section{Perception of Risk in Intimacy and Interpersonal Relationships}

Some individuals have difficulty developing intimate relationships. When people fail to develop and maintain intimacy in relationship, they tend to feel lonely and depressed (Prager \& Buhrmester, 1998). Examples of people who have difficulty with intimacy are those who perceive high levels of risk in intimate relationships (Pilkington \& Richardson, 1988). In order to measure individual differences in the perception of the risks associated with intimacy, Pilkington and Richardson (1988) developed a measure called the Risk in Intimacy Inventory (RII). Research on risk in intimacy has shown that 
those who perceive greater risk in intimate relationships (high-RII individuals) believe that risky relationship events are more likely to occur than non-risky relationship events and perceive ambiguous situations as involving more rejection and negative outcomes than do those who do not perceive high levels of risk in intimacy (low-RII individuals; Pilkington \& Woods, 1999).

In order to understand the extent to which cognitive factors underlie perceptions of risk in intimacy, Pilkington and Woods (1999) asked participants to complete several tasks using a computer program that recorded response times. First, participants were given several relationship situations, which they were asked to classify as either risky or non-risky. They were also asked to indicate the degree to which several ambiguous scenarios were due to interpersonal aspects (i.e., due to romantic interest or rejection) or impersonal factors (i.e., being polite or an unexpected delay). Finally, participants were also asked to rate a list of relationship events according to how risky they are and how likely they are to occur. As previously mentioned, Pilkington and Woods (1999) found that high-RII individuals perceived risky events as more likely to happen than non-risky events. They also believed that ambiguous situations were more likely to involve rejection, even when they were presented with a non-rejecting alternative. In addition, high-RII participants indicated that romantic relationships present greater danger than did low-RII participants. In Pilkington and Wood's (1999) study, high-RII females arrived at the negative interpretation of events significantly faster than did low-RII females, indicating that a chronically accessible risk-in-intimacy schema was used to interpret the ambiguous social situations. The same interpretation also accounts for Pilkington and 
Wood's (1999) finding that high-RII men classified risky versus non-risky events significantly faster than did low-RII men.

Additional research on risk in intimacy has demonstrated that social interactions are uncomfortable for high-RII individuals. For example, high-RII people have been found to have shorter and more numerous encounters with others, whereas low-RII individuals tended to have fewer and longer encounters with others (Nezlek \& Pilkington, 1994). This indicates that high-RII individuals limit their potential for intimate contact by having quick, superficial conversations with others (Nezlek \& Pilkington). That is, their contact with others may not last long enough to develop intimacy. Relationships tend to begin with the exchange of superficial information (Altman \& Taylor, 1973). Gradually, disclosures become more personal and meaningful through subsequent interactions (Altman \& Taylor, 1973). Thus, if high-RII people indeed limit their interactions with others to quick and superficial conversations, then the possibility of developing an intimate relationship with another person is decreased. Consistent with this notion, highRII individuals have reported that their encounters are less intimate and enjoyable than have low-RII people (Nezlek \& Pilkington). In addition, high-RII individuals reported feeling less confident in their social interactions and believed that they have less influence over these interactions than did low-RII individuals (Nezlek \& Pilkington). Taken together, these results suggest that high-RII people often feel that their needs are not met during their interactions with others.

Nezlek and Pilkington (1994) also found that the influence of perceptions of risk in intimacy on participants' feelings during their interactions with others depended, in part, on who those others were. For example, high-RII and low-RII women did not differ 
in their evaluations of interactions with romantic partners. However, high-RII women felt more negatively about their encounters with opposite-sex friends than did low-RII women. High-RII men, on the other hand, felt more positively about their interactions with their opposite-sex friends, whereas low-RII men felt more positive about their interactions with romantic partners. Nezlek and Pilkington explain that sex role stereotypes may account for this finding. That is, women are traditionally responsible for maintaining intimacy in romantic relationships. Having the responsibility of maintaining intimacy may help high-RII women overcome their anxieties about intimacy and act in accordance with low-RII women. Men, on the other hand, are stereotypically required to restrain emotion. This may increase high-RII men's negative feelings when they are involved in romantic interactions because they are required by the norms of this type of relationship to be more open and emotional. It is perhaps because of this fear of developing romantic relationships that high-RII individuals tend to have smaller opposite-sex social networks than do low-RII people (Nezlek \& Pilkington, 1994).

High-RII people have also been found to limit their self-disclosures to strangers (Pilkington, 1995). Self-disclosure occurs when people reveal personal information about themselves and express their emotions, needs, thoughts, attitudes, and beliefs (Chelune, 1977). In this way, they open themselves up to others (Meeks, Hendrick, \& Hendrick, 1998). However, high-RII people tend to have risk schemas readily accessible (Pilkington \& Woods, 1999); it is probably for this reason that high-RII people report that they are less relaxed and more worried about the impression they are making on others than do low-RII people when they talk to strangers (Brunell, 2001; Pilkington, 1995). In other words, it is likely that high-RII people are less relaxed and more worried about the 
impression they are making because they fear rejection from the stranger. Thus, when high-RII people meet someone who discloses about him/herself at an intimate level, they are not very relaxed about the intimacy involved in their interaction because they feel pressured to reciprocate the person's intimate disclosure with their own intimate disclosure (Brunell, 2001; Pilkington, 1995).

\section{Self-Disclosure and Social Penetration Theory}

High-RII people's discomfort with the self-disclosure process is problematic because self-disclosure has been found to be a necessary step in the development of intimacy in relationships (Altman \& Taylor, 1973; Prager, 1995; Reis \& Shaver, 1988). For example, Altman and Taylor (1973) describe the process of social penetration as a means of gradually developing intimacy with another person. According to social penetration theory, most relationships are believed to begin with the exchange of superficial information, which gradually turn into meaningful disclosures. Thus, researchers believe that relationship development is linked with systematic changes in communication patterns (Altman \& Taylor, 1973). When superficial conversation is rewarding, people are likely to move the conversation to a deeper level by increasing the breadth (the number of topics) of the conversation and the depth (the personal significance of the topics) of the conversation.

Early interactions in a relationship usually involve self-disclosure reciprocity. That is, new acquaintances tend to match one another's disclosures (e. g., Derlega, Wilson, \& Chaikin, 1976; Dindia, 2000). In other words, when one partner is open, the other is open as well, and when one partner's disclosures increase in intimacy, the other partner's disclosures tend to increase in intimacy as well. Thus, because self-disclosure 
tends to be reciprocal, it not only influences, but also is influenced by the intimacy two people experience. In addition, self-disclosure reciprocity can function as both a reward and a cost during the acquaintanceship process. The reception of self-disclosed material is rewarding and people who self-disclose tend to be better liked (Daher \& Banikiotes, 1976). However, other evidence suggests that certain factors can affect the reward outcomes of disclosure and interpersonal attraction. Cozby (1973), for example, has shown that a person who discloses at a medium level of intimacy is liked better than a person who discloses at low or high levels. Chaikin \& Derlega (1974a; 1974b) also have found that social norms regulate an individual's level of self-disclosed intimacy and how much that individual is liked. Although a person who discloses at exceptionally high levels is liked less than a person who discloses at medium levels, the person who discloses at high levels is liked more than a person who reciprocates an intimate disclosure with a relatively superficial one (Chaikin \& Derlega, 1974a).

Although receiving a disclosure from another person is rewarding, it is possible that similarity in disclosure level may also function as a reward. That is, individuals appear to be socially rewarded when they find out that others are similar to them (e.g., Daher \& Banikiotes, 1976). For example, the amount of disclosure received appears to be effectively rewarding only when coupled with conditions of similar content. In fact, Daher and Banikiotes found that when disclosures were dissimilar in content, varying amounts of disclosure did not affect people's propensity for attraction. However, when the disclosure was similar in content, people tended to display a greater attraction for their conversational partner in the high-disclosing condition. 
When a relationship is already established, self-disclosure reciprocity occurs significantly less often, and one person's deep disclosure may not be reciprocated for a longer period of time (e.g., Derlega et al., 1976). Thus, as a relationship develops, reciprocity becomes less important. Instead, responsiveness becomes the more important factor for the maintenance of intimacy in a relationship (Reis \& Patrick, 1996). Once relationships are established, people want their partners to demonstrate sympathy and understanding when they disclose (Sprecher, Metts, Burleson, Hatfield, \& Thompson, 1995). They also want to feel that their partners understand, support, respect, and care for them when they reveal private information about themselves (Laurencau, Barrett, \& Pietromonaco, 1998).

\section{Reis and Shaver's Model of the Intimacy Process}

Research on self-disclosure has led Reis and Shaver (1988) to propose a model of the development of intimacy. According to Reis \& Shaver's (1988) model of intimacy, two people influence one another's feelings and behaviors over time and over a number of interactions. Several factors determine whether or not an interaction will be intimate or not. These factors include (a) an individual's motives, fears, and goals for an intimate interaction, (b) the individual's self-disclosure and expression of emotions, (c) the partner's own motives and interpretive filter of the individual's behavior, (d) the partner's response to the individual's disclosure, and (e) the individual's interpretive filter and reactions to the partner's response to his or her behavior. Each of these steps occurs during a single interaction between two individuals.

The first step involves the individual's motives, fears, and goals for an intimate interaction. A person may seek intimacy for various reasons. Reasons to seek intimacy 
include wanting affection, self-understanding, and self-validation. A person may want to share feelings, elicit guidance or advice, feel less lonely (Mehrabian \& Ksionzky, 1974) and/or establish a sense of belongingness (Baumeister \& Leary, 1995). According to McAdams (1985), people are motivated to establish intimacy in their lives. The intimacy motive is "a recurrent preference or readiness for warm, close, and communicative exchange with others - an interpersonal interaction perceived as an end in itself rather than as a means to another end" (McAdams, 1985, p. 87). Behaviors that lead people to engage in intimate interactions have been described by some researchers as approach tendencies (e.g., Gable \& Reis, 2001).

However, along with the motive to establish intimacy with others can stem a fear that is associated with intimacy. Gable and Reis (2001) describe behaviors that keep people from becoming intimate as avoidance tendencies. Reasons to avoid intimacy include the fear of being exposed, abandoned or rejected, losing control, and being manipulated (Hatfield, 1984). As Reis and Shaver (1988) describe, people have both approach and avoidance tendencies. The way a partner responds to an individual can elicit an individual's approach and/or avoidance tendencies. These tendencies, in turn, influence how the individual regulates self-disclosure and expression of thoughts and feelings in order to test the partner's responsiveness (Reis \& Shaver, 1988).

The second step in the interaction is the individual's disclosure. According to Reis and Shaver (1988), the disclosure of personal desires, fantasies, anxieties, and emotions is more important for the development of intimacy than is the disclosure of facts because the disclosure of emotions provides an opportunity for the partner to validate and demonstrate that he or she cares for, supports, and accepts the individual. 
Fitzpatrick (1986) has demonstrated the importance of emotional self-disclosure; he argued that once partners get to know each other, communication of feelings is the fundamental predictor of relationship satisfaction.

The third step in the process involves the way the partner perceives the individual's behavior. The partner, playing the part of responder in the current situation, brings his or her concerns and interpretive tendencies into the interaction with the individual (Reis \& Shaver, 1988). That is, the partner comes into a given situation with a set of expectations and schemas that may influence his or her behavior towards the individual. The way the partner interprets the individual's disclosures and behaviors can have an impact on how the partner responds to the individual.

The fourth step involves the partner's response to the individual's disclosure. The partner's response to the individual is as important as the individual's initial disclosure in determining whether an interaction will become intimate (Reis \& Shaver, 1988). Appropriate responsiveness enhances feelings of connectedness, whereas nonresponsiveness tends to decrease intimacy in an interaction. Responsiveness facilitates further communication; nonresponsiveness is an indicator that a person is uninterested (Miller \& Berg, 1984).

After the partner responds to the individual, another factor involved in whether or not the interaction will become intimate is the individual's interpretation of and reaction to the partner's behavior (Reis \& Shaver, 1988). If the individual perceives his or her partner's behavior to be unsupportive or intrusive, it is unlikely that the interaction will become intimate. Thus, in order for an individual to experience an interaction as intimate, he or she must perceive the partner's response to be understanding, validating, 
and caring. When this is the case, the individual may disclose again, or may prompt the partner to disclose and allow the individual to play the role of responder. If no restrictions prevent the two partners from exchanging roles of discloser and responder, an interaction between the two is likely to become increasingly more intimate (Reis \& Shaver, 1988).

\section{Prager's Three-Component Definition of Intimacy}

Prager (1995) has also defined intimacy in terms of self-disclosure. According to Prager (1995), intimacy found in a given interaction is a function of three components. Partners involved in an interaction must (a) reveal personal or private information, (b) feel positively about themselves, their interaction partner, and the interaction itself, and (c) perceive that the interaction increased or reflected the two partners' understanding of one another (Prager, 1995). Prager's (1995) definition of intimacy focuses on interactions as opposed to relationships because interactions are related to specific behaviors, feelings, and perceptions. Interactions are also connected to relationship development and incorporate the behaviors and experiences that people identify with intimacy, such as confiding and listening (Prager, 1995).

In their research, Prager and Buhrmester (1998) found that intimate communication contributed to individual need fulfillment. They found that men and women who communicated openly with their romantic partners and had frequent sexual and affectionate interactions perceived more love and affection, companionship, belonging, and nurturance in their relationship than did those who engaged in these activities less frequently. In particular, Prager and Buhrmester (1998) also found that women's communal needs (i.e., their sense of openness and union) were met most 
frequently when partners listened attentively to one another's disclosures. In addition, Prager and Buhrmester found that couples who self-disclosed, despite negative interactions, tended to have higher levels of communal need fulfillment than did those who failed to disclosure during negative interactions. When it came to need fulfillment, self-disclosure appeared to reduce the effects of negative affect by ensuring that communal need deprivation did not result from a negative interaction. In other words, rather than finding that self-disclosure enhanced need fulfillment when interactions were positive, self-disclosure appeared "to buffer of the couples' interactions on partners' communal need fulfillment" (p. 465) when interactions were negative due to quarrelling or criticism.

Additional research by Lippert and Prager (2001) addressed how relationship partners' working definitions of intimacy (definitions people use to classify and evaluate what happens to them in their relationships) emerge from experiences in daily interactions. They found that couple's working definitions of intimacy involved pleasantness when interacting, disclosure of personal or private information and emotions, feeling understood by one's partner, and the expression of positive feelings about the partner. Moreover, interactions that contained these characteristics were perceived as the most intimate. Those who reported greater relationship satisfaction reported that their interactions with their partners were more intimate than did those who reported less relationship satisfaction. In addition, people who associated their partner's private disclosures with the expression of intimacy were also more satisfied in their relationship than were those who associated their partner's disclosures less with experiences of intimacy. 


\section{Self-Disclosure, Intimacy, and Relationship Satisfaction}

As Prager and her colleagues (Lippert \& Prager, 2001; Prager, 1995; Prager \& Buhrmester, 1998) have demonstrated, romantic relationships are specific examples of relationships in which intimacy is essential. Several other researchers have also demonstrated that a couple's ability to engage in intimate conversation is an important factor that leads to the development of intimacy (e.g., Clark \& Reis, 1988; Rubin, Hill, Peplau, \& Dunkel-Schetter, 1980). In fact, experiencing intimacy through disclosure may be the most important interpersonal factor that determines couple adjustment (Waring, 1981). In addition, according to Murstein (1974), a major problem in marriage is that while dating, couples fail to disclose attitudes, personal values, and beliefs that can be indicative of conflicting value systems. Finding out that a partner or spouse has different values from one's own can prevent closeness. In contrast, finding out that a partner or spouse has similar values as one's own can increase closeness. Thus, information that is exchanged between relationship partners is critical to relationship development (Berger, 1988). According to Berger (1988), exchanging information is a necessary step towards uncertainty reduction, which incorporates one's ability to predict and explain other people's actions.

As previously mentioned, self-disclosure is rewarding (e.g., Daher \& Banikiotes, 1976) and romantic relationships that encompass more extensive and intimate selfdisclosure tend to be more rewarding relationships (Meeks et al., 1998). This is probably why spouses who disclose at higher levels to one another also report greater marital satisfaction (Meeks et al., 1998). Self-disclosure is facilitated when the material disclosed is perceived as appropriate in the context of the relationship and the listener is perceived 
as supportive and willing to disclose in a reciprocal pattern (Waring, 1981). When couples engage in high levels of self-disclosure, they feel they can open up to their partners and also feel that their partners open up to them (Meeks et al., 1998). Both are crucial for building and maintaining intimacy, but which factor is more important is unclear. Meeks, et al. (1998) found that one's own self-disclosure is the more important factor. However, Sprecher (1987) found that the best predictor of love for partner was how much individuals perceived their partners as disclosing to them. Perhaps partners feel they are involved in an intimate relationship when they can express their thoughts, opinions, and feelings to their partners, and feel their partners are able to express themselves as well.

Historically, women were believed to be more expressive than were males. Their traditional social role was defined as disclosing feelings and attitudes, and they were responsible for establishing intimacy in the relationship. However, over time, the traditional male role has been modified into the modern male role. The "modern male" may increase emotional intimacy in the context of close heterosexual relationships (Rubin, et al., 1980). As a result, modern couples tend to exhibit patterns of full and equal self-disclosure. In the past, couples may have reserved more of their thoughts and feelings while they were dating and even after marriage. In contrast, the current generation seems to view reciprocal intimate disclosure as an integral part of a close, opposite-sex relationship. The ability for both partners to disclose about themselves more fully has produced relationships that foster mutual respect and trust (Rubin et al., 1980). Thus, in general, romantic relationships that contain a high level of self-disclosure 
have been found to be both more intimate and more satisfying for both partners (e.g., Meeks et al., 1998; Prager, 1989).

\section{The Present Investigation}

Given that romantic relationships are defined by intimacy, and intimate interactions are difficult for high-RII people, it was expected in the present study that higher levels of risk in intimacy would be associated with lower levels of intimate interactions. This hypothesis is consistent with social penetration theory (Altman \& Taylor, 1973), Reis and Shaver's (1988) model of intimacy, and Prager's (1995) definition of intimacy. According to social penetration theory (Altman \& Taylor, 1973), the superficial exchange of information gradually develops into deeper, more meaningful disclosures. However, high-RII people have been demonstrated to limit their disclosures to strangers (Pilkington, 1995), thus preventing social penetration from occurring. In addition, Nezlek and Pilkington (1994) have demonstrated that high-RII individuals limit contact with others by having quick, superficial conversations. Thus, high-RII people are probably less likely to be intimate in a romantic relationship because they prevent the social penetration process from occurring with their romantic partners. In addition, although high levels of self-disclosure have been found to be rewarding for many (e.g.,

Daher \& Banikiotes, 1976; Keelan et al., 1998; Meeks, et al., 1998; Mikulincer \& Nachshon, 1991), this is probably not the case for high-RII individuals, who have been shown to feel negatively about intimate conversations with others (Brunell, 2001; Pilkington, 1995).

In addition, the hypothesis that higher levels of risk in intimacy would correspond to decreased levels of intimacy in romantic relationships is consistent with Reis and 
Shaver's (1988) model of intimacy. Because high-RII people have been shown to (a) perceive romantic relationships to be extremely risky, (b) be likely to bring their risk-inintimacy schemas to bear in their interactions with their partner, and (c) have rejection expectations and schemas readily available (Pilkington \& Woods, 1999), they are probably more likely to engage in avoidance tendencies. If this is indeed the case, then it follows that high-RII people would be less likely to (a) disclose personal or private information to their partners, (b) express emotions to their partners, and (c) be adequately responsive to their partners. If this were true, then according to the Reis and Shaver model, the development of intimacy would be hindered.

Finally, the hypothesis that those who perceive higher levels of risk in intimacy would be less intimate in their romantic relationships is also consistent with Prager's (1995) definition of intimacy. As previously mentioned, Prager (1995) defined intimacy as revealing personal or private information, feeling positively about oneself, one's interaction partner, and the interaction itself, and perceiving that the interaction increased or reflected the two partners' understanding of one another. However, high-RII individuals are less likely to reveal personal or private information about themselves (Pilkington, 1995). They are also less likely to feel positively about themselves due to having lower levels of self-esteem (Pilkington \& Richardson, 1988). In addition, after revealing personal or private information, people with higher levels of risk in intimacy are less likely to feel positively about their partners (Nezlek \& Pilkington, 1994), and about their interaction (Brunell, 2001; Pilkington, 1995). Thus, if at least one partner is high in risk in intimacy, then the likelihood for the two partners to increase understanding for one another is likely to be diminished. 
Because high-RII people are uncertain of others, perceive romantic interactions to be riskier than other types of interactions, fear rejection, and bring their risk schemas to bear on ambiguous situations (Pilkington \& Woods, 1999), the second hypothesis was that the more risk in intimacy a partner perceived, the less likely he or she would be to trust his or her partner. Finally, because high levels of trust and intimacy (as defined by disclosing personal information and emotions) are associated with increased relationship satisfaction, it was hypothesized that relationships that involve higher levels of risk in intimacy would be associated with lower levels of relationship satisfaction. The lack of relationship satisfaction is believed to stem from high-RII individuals' inability to establish the closeness that is necessary for a happy and successful romantic relationship.

\section{Method}

\section{Participants}

Participants were recruited through introductory psychology courses and were asked to bring their romantic partner to the lab to participate in the study. The participants were offered partial course credit in exchange for their participation, and their romantic partners were offered payment of $\$ 5$. In total, 64 couples participated. Thus, only 62 couples provided useable data. Couples were required to be in a romantic heterosexual relationship for at least six weeks in order to participate (mean length of relationship $=10.5$ months).

\section{Materials}

The Risk in Intimacy Inventory (RII; Pilkington \& Richardson, 1988) is a 10-item measure. Respondents use a 6-point scale to indicate the degree to which each item represents their feelings. Examples of these items are "It is dangerous to get really close 
to people," and "The most important thing to consider in a relationship is whether I might get hurt" (see Appendix A). The responses to these ten items are summed to produce an overall score. Internal reliability for the RII has ranged from $\alpha=.80$ to $\alpha=.89$ in previous research (e.g., Nezlek \& Pilkington, 1994; Pilkington \& Richardson, 1988). Internal reliability for the current sample was also high $(\alpha=.84)$. Total scores ranged from 10 to $50(M=24.47, S D=8.71)$; higher scores indicate greater perceived risk in intimacy.

Interpersonal trust was measured using Rempel, Holmes, and Zanna's (1985) interpersonal trust scale. Participants indicate how much they agree with a series of 17 statements on 7-point scales. Examples include "I can rely on my partner to keep promises that he/she makes to me," and "I feel very uncomfortable when my partner makes decisions that will affect me personally" (see Appendix B). Rempel, Holmes, and Zanna (1985) report adequate internal reliability of for the overall scale $(\alpha=.81)$. Internal reliability for the current sample was similar $(\alpha=.79)$. Total scores are computed by first reverse scoring responses to items $4,5,6$, and 16 and then summing all relevant items. Total scores for the current sample ranged from 45 to 107 ( $M=89.93$, $S D=11.20$ ). Higher scores correspond to higher levels of trust in one's partner.

Partners' overall relationship satisfaction was measured using a series of 13 questions that asks participants to indicate agreement to statements using 7-point scales. The first four items were adapted from Murray, Holmes, and Griffin (2000) and the last nine were used in Palen's (2001) study. Examples of statements included "I am extremely happy with our relationship" and "I do not like my partner" (see Appendix C). Total scores are computed by reverse scoring items $3,5,7,10$, and 12 and summing all 
relevant items. For the current sample, scores ranged from 50 to $92(M=82.70, S D=$ 9.49). Internal reliability for this sample was high $(\alpha=.89)$. Higher scores represent greater satisfaction.

The Emotional Self-Disclosure Scale (ESDS; Snell, Miller, \& Belk, 1988) consists of 40 items to assess emotional self-disclosure, or the direct, verbal communication of affective states to one's intimate partner. Items measure eight emotions: depression, happiness, jealousy, anxiety, anger, calmness, apathy, and fear. For each of the items, participants indicate on 5-point scales ( $1=$ not at all willing to discuss this topic, $5=$ totally willing to discuss this topic) how willing they would be to discuss each topic with their romantic partners (see Appendix D). Snell et al. (1988) reported internal reliabilities for the subscales to range from a low of .83 to a high of .95 . Overall scores are computed by summing all items. For the current sample, the internal reliability for the overall scale was high $(\alpha=.97)$. Scores ranged from 63 to $125(M=$ 104.90, $S D=16.48)$.

\section{Procedure}

Participants reported to the laboratory with their partners. Upon arriving at the laboratory, each couple was led into a comfortable room containing a couch, several chairs, a TV and a hidden video camera. Participants were told that the researcher was interested in studying discussions among couples that were both personal and impersonal in nature. Couples were allowed to seat themselves wherever they would be the most comfortable for the conversation portion of the study.

Following Guerrero's (1997) procedure, each partner was asked to list three impersonal and three personal conversational topics that they discussed frequently. The 
researcher suggested topics related to school/work, sports, and extracurricular activities for the impersonal list, and relationship issues, family, and feelings for the personal list. In addition to listing the topic, both partners listed separately how frequently they discussed each topic (very frequently, frequently, somewhat frequently). Each partner also used 5-point scales to indicate how personal each topic was ( $1=$ very impersonal and $5=$ very personal) and how important (defined as "how big of a deal") each topic was to him or her ( $1=$ not a very big deal, $5=$ a very big deal). Scores for personal and impersonal topics were averaged for each of these measures. On average, the participants rated the personal topics they listed as more personal $(M=4.41, S D=.53)$ than the impersonal topics they listed $(M=2.86, S D=.72), t(126)=23.54, p<.001$. The personal topics listed were also reported to be more important $(M=4.29, S D=.57)$ than were the impersonal topics listed $(M=3.40, S D=.66), t(126)=11.73, p<.001$. In addition, participants reported discussing personal topics $(M=2.15, S D=.51)$ less frequently than they reported discussing impersonal topics $(M=2.29, S D=.45), t(127)=2.63, p<.01$.

Participants were asked to use the topics they listed to initiate conversation, but were told that they were not restricted to discussing these topics. According to Guerrero (1997), "this informal structure increases subject comfort and encourages more natural behavior displays" (p. 39). During the first two minutes partners discussed the impersonal topics and during the last six minutes they discussed the personal topics. The researcher instructed the couple to begin their conversation about the impersonal topic(s) as soon as he or she left the room. The researcher also instructed the couple to listen for two knocks on the door. The first knock signaled the switch to personal topics, and the 
second indicated the end of the discussion session. The researcher emphasized that the goal was for the interaction to be as natural as possible.

At the end of the discussion session, the researcher brought one partner into another room so that each partner would be able to privately answer the questionnaires. The questionnaires included a post-disclosure questionnaire which asked participants to rate on separate 7 -point scales $(1=$ not at all and $7=$ very much $)$ their perceptions of how much they disclosed and how much emotion they expressed to their partner during their conversation; how much they felt their partner disclosed and expressed emotion to them; how accepted, understood, and cared for they felt during their conversation; how much closeness they felt during the conversation; and how much they and their partners disclosed facts, thought, and emotions (see Appendix E). The researcher told each partner that his or her answers would be completely confidential; no answers would be shared with his or her partner. After completing the questionnaires, permission to use the videotapes was secured and both partners were debriefed and thanked for their participation.

\section{Videotape Coding System}

A male and a female were trained to code all couples' videotapes along the dimensions of depth, emotional investment, responsiveness, and involvement in the conversation on 5-point scales. Both coders were blind to participants' levels of perceptions of risk in intimacy. The coders made separate ratings for each partner every two minutes during the course of the conversation, resulting in four assessments per partner. At the end of the eight-minute segment, coders also rated how intimate the conversation became and how close the couple seemed while conversing. Bartko's 
(1976) intraclass correlations (ICCs) were computed to determine the inter-rater reliability of these ratings.

Depth of conversation was defined as the amount of intimate information disclosed about a topic, based only on the information disclosed and not on the degree of emotion expressed (Shaffer et al., 1982). Coders followed Archer and Berg's (1978) definitions of the key properties of intimacy. That is, biographical characteristics were considered low in depth; attitudes and opinions were intermediate in depth, and fears, self-concepts, and basic values as high in depth. Additionally, coders were instructed to consider the privacy of the information disclosed; disclosures that were high in depth were considered those which communicated private, generally unknown information about oneself that is otherwise unavailable to others (Archer \& Berg, 1978; Morton, 1978). The four depth ratings per partner were summed to create an overall depth measure: $\mathrm{ICC}=.82$, for the two coders.

Emotional investment was defined as the intensity of emotion communicated on a topic. The coders made their ratings based on such speech characteristics as intonation and hesitations (Shaffer et al., 1982). The four emotional investment ratings per partner were summed to create an overall emotional investment measure. Inter-rater reliability for emotional investment was low and therefore emotional investment is not considered in subsequent analyses.

Responsiveness was defined as the extent to which each partner responded to the other during the course of the conversation. Examples of responsiveness are responses such as "uh-huh," "yeah," "I understand," and "I know what you mean". The four 
responsiveness ratings per partner were summed to create an overall responsiveness measure: $\mathrm{ICC}=.99$.

Involvement in the conversation was defined as the extent to which each partner was interested in talking, showed enthusiasm while talking, and seemed to find the conversation stimulating (Burgoon \& Hale, 1987). The four involvement ratings per partner were summed to create an overall involvement measure: $\mathrm{ICC}=.89$.

Ratings were not made for depth and emotional investment if a person primary listened during a two-minute segment. Ratings for responsiveness were not made if a person primary talked during a two-minute segment.

Coders also indicated whether each partner disclosed more information or facts about themselves, more feelings and thoughts, or an even amount of both during the conversation for each of the four two-minute segments. In addition, at the end of the eight-minute segment, coders rated which partner did most of the talking (the male, the female, or both talked equally) and whether or not the couple argued during their conversation. Kappa was used to compute rater reliability. Kappa for all of these measures was low $(<.65)$. Therefore, these measures will not be considered for further analysis.

\section{Results}

\section{Analytic Strategy}

Gonzalez and Griffin (2000) discuss four common errors researchers make when evaluating the relationship between two variables from dyadic data. The first, the "assumed independence error" is when researchers treat interdependent data points like they are independent. The second is the "deletion error" which occurs when researchers 
throw out half of their sample in order to create independent data. The third, the "crosslevel error," is when individual scores are aggregated to represent the dyad. The "crosslevel error" is problematic because correlations between dyadic averages can be different from the correlation computed for individual scores. Finally, researchers collecting dyadic data need to avoid the "levels of analysis error," which occurs when researchers interpret the correlation between dyad means as indicating processes at the dyadic level and the correlation between individual scores as indicating processes at the individual level. Both processes at the dyadic level and at the individual level contain a mix of dyad-level and individual-level information.

The alternative technique to avoid committing the errors mentioned above is called the "pairwise method," which permits significance tests that adjust for the observed degree of interdependence within the dyads (Gonzalez \& Griffin, 2000). In addition, there are several advantages to using the pairwise approach. First, it allows researchers to ask questions at both the dyad level as well as the individual level at the same time. Second, researchers are able to use data from both members of a dyad. Third, the pairwise approach appropriately adjusts for the degree of interdependence in the dyad members' responses when testing for significance of a correlation or regression.

When computing a pairwise intraclass correlation, data is first set up to account for possible within-group pairings. The data in the current sample consists of distinguishable cases because gender was used to identify individuals within the couple. Thus, each couple was represented twice. The first time, the male data represents the participant and the female represents the partner, and the second time, the female data represents the participant and the male data represents the partner. 
One set of correlations that can be computed with the pairwise technique is $r_{x_{x} \cdot c}$; $\mathrm{x}$ represents an individual's score on variable $\mathrm{x}$ and $\mathrm{x}$ ' represents the partners score on the same variable, and $\mathrm{c}$ represents the variable that is partialled out. For each variable in the current study, partial correlations are computed between participants' and partners' scores, controlling for gender. Because the correlation $r_{x x^{\prime} \cdot c}$ is based on $2 \mathrm{~N}$ pairs rather than on $\mathrm{N}$ dyads, the significance test needs to be adjusted. To make this adjustment, $r_{x x} \cdot c$ can be tested against the null hypothesis that $P_{x x^{\prime} \cdot c}=0$ using the following asymptotic test:

$$
Z=r_{x^{\prime} \cdot c} \sqrt{ } N
$$

$\mathrm{N}$ represents the number of dyads and $\mathrm{Z}$ is normally distributed and can be compared to critical values found in standard tables.

A second set of correlations that can be computed is correlations over all individuals between the variables $\mathrm{x}$ and $\mathrm{y}$, which is called the overall within-partner correlation. This correlation is represented by $r_{x y . c}$, where $\mathrm{x}$ represents an individual's score on variable $\mathrm{x}$, and $\mathrm{y}$ represents the same individual's score on variable $\mathrm{y}$. Under the null hypothesis that $\mathrm{P}_{\mathrm{xyc} . \mathrm{c}}=0$, the effective sample size has to be calculated for $\mathrm{N}$ according to the following formula:

$$
\mathrm{N}^{*}=\frac{2 \mathrm{~N}}{1+\mathrm{r}_{\mathrm{xx} \cdot . \mathrm{c}^{\prime} \mathrm{y}^{\prime} \cdot \mathrm{c}}+\mathrm{r}_{\mathrm{xy} \mathrm{y}^{\prime} \cdot \mathrm{c}}^{2}}
$$

The partial overall correlation $r_{x y . c}$ can be tested using the following $Z$ test:

$$
\mathrm{Z}=\mathrm{r}_{\mathrm{xy} . \mathrm{c}} \sqrt{ } \mathrm{N}^{*}{ }_{1}
$$

A third set of correlations that can be analyzed is between an individual's score on $\mathrm{x}$ with his or her partner's score on $\mathrm{y}$, which is called the cross-intraclass correlation. In other words, is an individual's score on one variable related to the partner's score on 
another variable? This correlation is represented by $\mathrm{r}_{\mathrm{xy}} \cdot \mathrm{c}$, where $\mathrm{x}$ represents an individual's score on variable $\mathrm{x}$ and $\mathrm{y}$ ' represents the partner's score on variable $\mathrm{y}$. Under the null hypothesis that $P_{x y ' . c}=0$, another effective sample size has to be calculated for $\mathrm{N}$, according to the following formula:

$$
\mathrm{N}^{*}=\frac{2 \mathrm{~N}}{1+\mathrm{r}_{\mathrm{xx} \cdot \mathrm{c}^{\prime} \mathrm{yy}^{\prime} \cdot \mathrm{c}}+\mathrm{r}_{\mathrm{xy} \cdot \mathrm{c}}^{2}}
$$

The partial cross-intraclass correlation $r_{x y^{\prime} \cdot c}$ can be tested using the following $Z$ test:

$$
\mathrm{Z}=\mathrm{r}_{\mathrm{xy} \cdot \mathrm{c}} \cdot \sqrt{\mathrm{N}^{*}}{ }_{2}
$$

Analyses for the Impersonal Versus Personal Conversations

One couple's conversation was not coded because they spoke in a foreign language. Another couple's conversation was not coded because they did not provide consent to use their videotape.

As previously mentioned, two raters coded couples' videotaped data for depth of the conversation. For the first two minutes, participants had been asked to discuss topics of an impersonal nature. The last six minutes, the couples discussed personal topics. Coders made assessments three separate times during the six-minute personal conversation. Ratings for the two coders were averaged to create scores for the impersonal conversation and three separate scores of the personal conversation. The three scores for the personal conversation were then averaged to create overall personal conversation measures of depth. In order to ensure that the conversation of the impersonal topics contained less depth than the conversation of the personal topics, a repeated measures analysis of variance was computed for each variable separately for males and females. For males, the impersonal conversation was rated as containing 
significantly less depth $(M=2.16, S D=.10)$ than the personal conversation $(M=2.79, S D$ $=08) ; F(1,47)=33.72, p<.001$. Females also disclosed in less depth during the impersonal topics conversation $(M=2.32, S D=.09)$ than during the personal topics conversation $(M=3.09, S D=.07), F(1,55)=66.89, p<.001$. The impersonal topics were used to initiate conversation in the lab and do not address the topic of the current investigation, which focuses on intimate conversation. In addition, the impersonal topics were found to be significantly different from the personal topics. Thus, the first two minutes concerning the impersonal conversation were removed from further analysis. All further analyses incorporate only the assessments from the personal conversation. Scoring

Intimacy was assessed several ways in the current study. First, there were assessments for depth of conversation each couple's videotaped interaction. Second, following the videotaped conversation, participants completed questionnaires that assessed how much they thought they disclosed and expressed emotions during the conversation, how much they believed their partners disclosed and expressed emotions during the conversation, and how accepted, close, understood, and cared for the participant felt by his or her partner during the conversation. Finally, self-reported measures of emotional self-disclosure were also completed.

Responses to the questions regarding how much the participant reported disclosing during the videotaped interaction and how much he or she reported expressing emotions were significantly correlated, $r=.56, p<.001$. Thus, these two scores were summed to create an overall self-reported disclosure score. Responses to the questions regarding how much the participant perceived his or her partner as disclosing and as 
expressing emotions were also significantly correlated, $r=.57, p<.001$. Thus, these two scores were summed to create an overall reported score of partner disclosure.

A principle components analysis was computed on responses to the four questions regarding how accepted, close, understood, and cared for the participant felt by his or her partner during the conversation. This analysis yielded one factor with an eigenvalue of 3.06 , which accounted for $76.50 \%$ of the variance. All items had a loading greater than .83. Thus, these four items were summed to create an overall partner warmth measure. Analyses Regarding Intimacy

For ease of discussion, in the following analyses, A will be used to represent the individual and B will be used to represent the partner when reporting the following results.

The focus of the current thesis was to assess if RII was related to intimate communication, and if intimate communication was related to relationship satisfaction. Intimate communication was assessed at two separate levels: at the specific level through the 6-minute videotaped interaction segment and at the more general level through the Emotional Self-Disclosure Scale (Snell et al., 1988). In addition, intimate communication at the specific interaction level was assessed three ways: through the coders' ratings of depth, A's self-report of his depth (or B's self-report of her depth), and A's report of B's depth (or B's report of A's depth).

The first set of analyses was computed to determine how A, B, and the coders perceived A's behavior during the videotaped interaction. (See Figure 1.) The coders' rating of A's depth during the conversation was related to A's self-report of his/her own depth. The coders' rating of A's depth was also related to B's perception of A's depth. 
In addition, A's report of his/her own depth was related to B's report of A's own depth. Thus, according to this triangulation, the coders agreed at some level with A's perception of his/her own behavior and with B's perception of A's behavior. In addition, B's perception of A's behavior was consistent with A's perception of his/her own behavior.

Moreover, the coders' rating of A's depth was correlated with the coders' rating of B's depth. This pairwise correlation was significant, $r_{x x} \cdot c=.83, p<.0001$, indicating that the coders' rating of A's depth was positively related to coders' rating of B's depth. In addition, A's report of his/her depth was related to B's report of his/her depth, $r_{x x} \cdot c=$ $.27, p<.02$. Finally, A's report of B's depth was positively related to B's report of A's depth, $r_{x x ' c}=.22, p<.04$. Thus, the three scores for intimacy indicated consistency between $\mathrm{A}$ and $\mathrm{B}$ regarding their disclosure during the videotaped interaction. However, A's RII was not related to B's RII, $r_{x x} x_{c}=.05, p=.35$. This finding was consistent with previous research (Palen, 2001). Because the partners' RII scores were independent, results can be discussed from either perspective. The perspective of A will be used.

The next set of analyses was computed to evaluate A's RII and his/her three intimacy scores at the interaction level. (See Figure 2.) A's RII was not related to the coders' rating of his/her depth. However, A's RII was negatively related to his/her selfreported depth and to B's report of A's depth. Thus, it appeared that A and B both somehow perceived A's RII as being related to his/her behavior, whereas a third party was unable to observe this relationship.

Table 1a reiterates the finding that A's RII did not relate to the coders' rating of A's depth. However, A's RII was significantly related to the coders' rating of B's depth, indicating that the higher A's RII, the less depth the coders perceived in B's 
communication. Additional analyses investigated whether A's RII was related to A's perception of B's warmth during their interaction, in addition to both A's and B's relationship satisfaction. Not only was A's RII negatively related to his/her perception of B's warmth, but A's RII was also negatively related to both A's and B's satisfaction. These analyses indicated that the higher A's RII, the less warmth he/she perceived in B and the less satisfied he/she was in his relationship with B. In addition, the higher A's RII, the less satisfied B was with the relationship as well. It is also important to note that neither the coders' ratings of A's depth nor the coders' ratings of B's depth were related to A's perception of B's warmth. The coders' ratings of A's and B's depth were also not related to A's and B's relationship satisfaction. However, A's perception of B's warmth was positively related to both A's and B's relationship satisfaction. Thus, this analysis revealed that the less warmth A perceived in B, the less satisfied A was in the relationship and the less satisfied B was in the relationship as well. As to be expected, A's relationship satisfaction was positively related to B's relationship satisfaction. According to the above analyses, it appears that the model shown in Figure 3a could be constructed to demonstrate the relationship of one person's RII to observers' rating of depth, the person's perception of his/her partner's warmth, and both partners' relationship satisfaction.

One would expect that the coders' rating of A's depth would be negatively related to A's RII. However, because RII appears to function at a cognitive level (Pilkington \& Woods, 1999), it is possible that it relates more to one's perception of his/her behavior as opposed to his/her overt behavior. Thus, it was hypothesized that A's RII would relate self-reports of depth, despite the lack of significance when coders' ratings of A's depth 
were used. For a set of new analyses, A's and B's self-reported depths replaced the coders' ratings of A's and B's depths in the above analyses. This new set of analyses revealed that A's RII was negatively related to both A's and B's self-reported depths. (See Table $1 \mathrm{~b}$ for these correlations.) In addition, the less depth A reported, the less warmth he/she perceived in B. Likewise, the less depth B reported, the less warmth A perceived in B. Thus, a second model is proposed in Figure 3b, which demonstrates that the higher A's RII, the less depth of communication both A and B reported. In addition, this model connects A's and B's reported depths to A's perception of B's warmth. A's report of B's warmth, in turn, was related to both A's and B's relationship satisfaction, as previously mentioned.

Because analyses addressed the individual's perspective, it was important to gain further insight by investigating the partner's perspective. Thus, A's report of B's depth and B's report of A's depth replaced their respective self-reported depths that were used in the analyses above. (See Table 1c.) A's RII was negatively related to both A's report of B's depth and B's report of A's depth. In addition, A's report of B's depth and B's report of A's depth were both positively related to A's report of B's warmth. Finally, B's perception of A's depth was directly related to B's satisfaction and A's report of B's depth was related to A's satisfaction. Due to the added relationships between report of partner's depth and one's own relationship satisfaction, a third model is proposed in Figure 3c.

In summary, the above analyses were used to investigate how A's RII was related to both partner's levels of intimacy during their interaction and their relationship satisfaction. A's RII was negatively correlated with the coders' rating of B's depth, but 
not with the coders' rating of A's depth. When A's and B's perspectives regarding their own behavior were assessed instead, A's RII negatively related to both partner's reported behavior. When A's and B's perspectives regarding their partner's behavior were analyzed, A's RII was also negatively related to both A's and B's perceptions of their partner's depth. In addition, A's RII was negatively related to his/her perception of B's warmth and to both A's and B's relationship satisfaction. Although the coders' ratings of A's and B's depths were not related to A's perception of B's warmth or either A's or B's relationship satisfaction, self-reported depth and report of partner's depth were related to these variables. More specifically, A's and B's self-reported depth both related directly to A's report of B's warmth. A's and B's reports of each other's depth both related to A's report of B's warmth and also to A's and B's own relationship satisfaction.

\section{Beyond the Single Interaction}

In order to generalize from the specific videotaped interaction to emotional disclosure in general, participants had completed the Snell et al. (1988) Emotional SelfDisclosure Scale (ESDS). As shown in Table 2, there was no significant relationship between the coders' rating of A's depth and A's ESDS. As previously mentioned, the coders' rating of A's depth was also unrelated to A's RII and both A's and B's relationship satisfaction. However, when a pairwise correlation was computed using A's self-reported depth, a positive relationship with A's emotional disclosure emerged. In addition, A's RII was negatively correlated with A's ESDS, indicating that the higher A's

RII, the less emotional disclosure to B he/she reported. As expected, A's ESDS was positively related to both his/her own relationship satisfaction and B's relationship satisfaction. 
Because A's emotional self-disclosure was related to his/her RII, A's satisfaction and B's satisfaction, another model is proposed in Figure 4. This model demonstrates that the higher A's RII, the less intimate he/she reported he/she was, both during one specific interaction and in general. In addition, the less emotional disclosure A reported in general, the less satisfied both A and B reported being in their relationship.

As previously discussed, high-RII individuals tend to fear being rejected, embarrassed, and betrayed by others (Pilkington \& Richardson, 1988; Pilkington \& Woods, 1999), indicating that they trust others less than do low-RII individuals. However, in order to disclose personal information about oneself, one must trust one's partner. Thus, trust in one's partner was assessed in this thesis using the Rempel et al. (1985) Interpersonal Trust Scale. As predicted, A's RII was negatively related to A's trust. (See Table 3.) Also as predicted, A's trust was positively related to A's ESDS. Finally, A's trust in B was related to both A's and B's relationship satisfaction. Due to the inter-relationships among the variables, another model is proposed in Figure 5a. This model demonstrates that the higher A's RII, the less he/she reported disclosing his/her emotions to B and the less trust he/she had in B. The less A disclosed his/her emotions to B and the less A trusted B, the less satisfied both reported they were in the relationship.

Considering the relationships that have emerged between B's satisfaction and both A's emotional disclosure and trust, it was necessary to examine the added relationships of B's emotional disclosure and trust. From these analyses, it is important to note that A's RII was not related to B's emotional disclosure. This finding is not consistent with the previous finding that A's RII was negatively related to B's perceived depth during their videotaped interaction. Two other inconsistencies also emerged. First, 
A's emotional disclosure was not significantly related to B's emotional disclosure, $r_{x x}{ }^{\prime} c=$ $-.07, p=.28$. Second, A's trust was not significantly related to B's trust, $r_{x x^{\prime} \cdot c}=.20, p=$ .14. However, despite these inconsistencies, A's trust was marginally related to B's emotional disclosure, $r_{x y^{\prime} \cdot c}=.14, p=.08$, indicating that the more trust A reported he/she had in B, the more B disclosed his/her emotions to A. In addition, A's RII was negatively related to B's trust in him/her, $r_{x y^{\prime} \cdot c}=-.27, p<.001$.

These additional analyses added to the model proposed in Figure 5a (See Figure 5b). The overall picture indicates that the higher A's RII, the less he/she reported disclosing his/her emotions, the less trust he/she had in $\mathrm{B}$, the less trust $\mathrm{B}$ had in $\mathrm{A}$, and the less satisfied they both were in the relationship. In addition, the less A reported disclosing his/her emotions, the less trust B had in A. The less A reported disclosing his/her emotions, the less satisfied A reported he/she was in the relationship. Likewise, the less B reported disclosing his/her emotions, the less satisfied A reported he/she was in the relationship. The less trust A reported he/she had in B, the less satisfied A and B had in the relationship. When A reported being satisfied in the relationship, so did B.

As previously mentioned, analyses for the variables of responsiveness and involvement in the conversation produced few significant results and are therefore not reported here.

\section{Discussion}

There are three sides to a story when two people interact- one person's side, the other person's side, and the way the situation actually happened. For the current thesis, the three sides of a couple's brief conversation were told. First, individuals reported how they perceived their own behavior during their conversation. Second, individuals 
reported how they perceived their partners' behavior. Finally, two unbiased observers reported how couples behaved by rating the video clips of their interactions. According to the triangulation, to some degree the observers, the individual (called A), and his/her partner (called B) agreed on how intimate the individual was during the interaction. However, A's perception of risk in intimacy was not related to A's observed behavior, but was related to both A's perception of his/her own behavior and B's perception of A's behavior. This finding is consistent with the notion that risk in intimacy operates at a cognitive level (Pilkington \& Woods, 1999). In addition, previous research on couple communication has indicated couples can establish their own language that is not easily deciphered by outside observers (Bruess \& Pearson, 1993). Thus, it appeared that individuals involved in a romantic relationship were able to subjectively perceive their own level of intimacy and/or their partners' level of intimacy as related to one partner's perception of risk in intimacy. As outsiders to the relationship, the coders were not privy to the language of the couple. Therefore, they might not have been able to fully detect the intimacy level of the discussion. However, it is important to note here that the coders' rating of depth was based solely on the information disclosed. By basing their ratings on information alone, it is possible that their ratings reflected the nature of the topic the couple chose to discuss, as opposed to the depth of the disclosures themselves. Perhaps if the videotapes were coded differently for depth, the observers may have been better able to understand the couples' communication patterns.

Moreover, coders were blind to how much risk in intimacy each partner perceived. Although partners may not be consciously aware of each other's perception of risk in intimacy, they most likely have more knowledge about it than the coders did. 
Interestingly, A's perceived risk in intimacy was negatively related to the coders' rating of B's intimacy, indicating that the coders perceived B as holding back his/her depth of communication as A's risk in intimacy increased. One possible explanation for this finding is due to B's level of comfort during the interaction. For instance, each couple had been instructed to discuss personal topics. One person most likely discussed these topics at a level that was consistent with his/her level of perceived risk in intimacy. However, if this person was more intimate than was normal for him/her, his/her partner may have been caught off guard. He/she may have responded by showing nonverbal cues of discomfort or by making the conversation less intimate. In contrast, if the partner perceived the individual as not being intimate, he/she may have displayed discomfort and decreased his/her own intimacy level to match the individual's intimacy level. This explanation was supported by the finding that one partner's level of intimacy was related to his or her partner's level of intimacy. In addition, this explanation is supported by the finding that B's report of A's behavior was negatively related to A's risk in intimacy. Thus, it is possible that A was comfortable during the interaction because he/she was behaving at a level that made him/her comfortable. However, because one partner was able to pick up on the other partner's perception of risk in intimacy and perceived him/her as not being intimate, the partner may have responded by decreasing his/her own intimacy. Thus, what the coders may have observed was not that A was holding back, but that B was.

Perceptions of risk in intimacy appear to operate at a cognitive level (Pilkington \& Woods, 1999). Thus, it was hypothesized that individuals' perception of their own intimacy and of their partners' intimacy would be related to RII scores. This was indeed 
the case. The higher A's perceived risk in intimacy, the less intimate A reported he/she was and the less intimate B reported he/she was. Thus, it appeared that both partners perceived themselves as responding to A's level of perceived risk in intimacy. In addition, the higher A's perceived risk in intimacy, the less intimate B reported he/she was and the less intimate A reported B was. Therefore, it also appeared that both partners perceived the other partner as holding back as A's perception of risk in intimacy increased.

Not only was A's level of risk in intimacy related to his/her self-reported depth and report of partner's depth, it was also related to A's perception of B's warmth, defined as feeling accepted, close, understood, and cared for by one's partner during the interaction. That is, the higher one partner's perception of risk in intimacy, the less warm he/she perceived his/her partner to be during their interaction. This finding is supported by previous research, in which high-RII individuals reported that their interactions were less intimate and that their interaction partners were less responsive to their needs and feelings, than did low-RII individuals (Nezlek \& Pilkington, 1994). The romantic relationship is the type of relationship that is defined as containing high levels of intimacy, and the perception of risk in intimacy construct is defined as fearing intimacy due to the rejection and betrayal that can come from exposing oneself to others (Pilkington \& Richardson, 1988; Pilkington \& Woods, 1999). Thus, it follows that the higher one's perceived risk in intimacy, the less positively one would likely feel about interactions with one's romantic partner. According to Prager's (1995) definition of intimacy, after disclosing, one should feel positively about oneself, one's partner, and one's interaction. For those with higher levels of risk in intimacy, this does not appear to 
be the case. Higher levels of risk in intimacy were related to lower levels of perceived partner warmth, and both high levels of risk in intimacy and low levels of perceived partner warmth were associated with lower levels of relationship satisfaction.

Both A's and B's reported intimacy were related to A's report of B's warmth. That is, the less accepted, understood, and cared for A felt, the less intimate A reported being during their interaction. In addition, the less warm A perceived $B$ to be, the less intimate B reported he/she was. Thus, to some extent, A may be accurate about B's warmth. This goes back to the triangulation, which demonstrated that relationship partners and observers agreed on individuals' behavior. However, when it came to relationship satisfaction, individuals' reports of their own behavior were not related to either partner's satisfaction, but individuals' reports of their partners' behavior was related to both partners' satisfaction. This finding was consistent with Sprecher's (1987) finding that how much people perceive their partners as disclosing was a more important factor than how much they perceived themselves as disclosing to their partners.

The finding that A's report of B's warmth was positively correlated with both A's and B's satisfaction was expected, as was the finding that A's perceived risk in intimacy was negatively correlated with both A's and B's satisfaction. First, in order to feel satisfied with one's relationship, it is important to perceive one's partner as caring and understanding. However, high-RII people were less likely to perceive their partners as caring and understanding than were low-RII people. Thus, it follows that high-RII individuals were less satisfied in the relationship.

The coders' rating of A's intimacy during his/her interaction with B did not relate to A's report of his/her emotional disclosure in general. This is to be expected. First of 
all, the coders rated depth as the amount of intimate information disclosed about a topic, based solely on the information disclosed and not on the degree of emotion expressed. Thus, coders' rating of depth was independent of A's emotional disclosure in the interaction or in general. Second of all, the perception of someone on the outside looking in is normally different from the perception of the person in the situation. Finally, for purposes of the study, participants had been asked to discuss personal topics, which is different from disclosing emotions in general.

In contrast, A's report of his/her behavior in the brief interaction with B was related to A's report of his/her emotional disclosure in general. To some extent, a person should perceive his/her behavior in one interaction as being consistent with his/her behavior in general. In addition, A's self-reported depth consisted of an aggregated measure of how much he disclosed during his interaction and how much he perceived himself as expressing his emotions during the interaction. The portion of the measure assessing how much A perceived himself as expressing his emotions during the interaction is similar to asking him how much he discloses his emotions to his partner in general. Thus, the aspect of expressing emotions should generalize from the specific interaction to interactions in general, and probably was the driving force behind the significant correlation.

Of greater interest was the finding that A's emotional disclosure was negatively related to his/her risk in intimacy score, indicating that the more risk in intimacy $\mathrm{A}$ perceived, the less he/she reported disclosing his/her emotions to B. Likewise, the higher A's risk in intimacy, the less trust he/she reported he/she had in B. In addition, A's emotional disclosure was related to his/her trust. Again, this finding was expected 
because having trust in one's partner is likely to be a necessary component in feeling safe disclosing feelings to that person. In other words, in order for someone to disclose personal feelings, he/she needs to feel that his/her partner is caring, supportive, and understanding. In addition, in order to disclose feelings, people must feel that their partners will not reject them or use the information against them. Thus, when people have high levels of trust in one's partner and feel that they can openly express what they are feeling, they feel satisfied in their relationship.

When people trust their partners and feel safe disclosing their feelings to their partners, they are not the only ones who are more satisfied with the relationship; their partners are more satisfied in the relationship as well. This is because when people feel they are trusted and perceive their partners as disclosing personal aspects of themselves, they know that they are liked/loved, which contributes to how satisfied they are in the relationship

Interestingly, Ass risk in intimacy was negatively related to B's trust in him/her. One would expect that the higher people's risk in intimacy, the less trust they would have in others, but it was unclear why people's risk in intimacy would correspond to their partners having less trust in them. Apparently, when someone perceives high risk in intimacy, they are not fully open with their partners about who they are and what they think and feel. This could, in turn, cause their partners to trust them less. Although A's risk in intimacy was related to both A's and B's trust, their levels of trust were not related to each other. This indicates that just because one partner is trusting of the other, it is not necessarily the case that the feeling is mutual. 
The purpose of the current thesis was to investigate the relationships among the variables of perception of risk in intimacy, intimate communication, and relationship satisfaction. Intimate communication was assessed both through the use of a videotaped segment of a couple's interaction as well as through self-report measures. As already discussed, perceptions of risk in intimacy not only related to intimate communication at the videotaped interaction level, but also at the more general level as assessed by the Emotional Self-Disclosure Scale and the Interpersonal Trust Scale. In addition, at the interaction level, A's satisfaction was found to be related to B's satisfaction with the relationship as well as to A's report of B's depth. This finding indicates that one's perception of one's partner's disclosure is a more important factor in relationship satisfaction than is one's own disclosure, which is consistent with Sprecher's (1987) study. However, at the general level, participants' own reported emotional disclosure was more strongly related to their relationship satisfaction than was their partners' emotional disclosure, which is consistent with the Meeks et al (1999) findings that one's own selfdisclosure is the more important factor in relationship satisfaction. Thus, which factor is more important for relationship satisfaction remains unclear.

It is important to note that depth at the interaction level and emotional disclosure in general may not actually represent the same construct. First of all, the context of the interaction should be taken into account. The laboratory interaction between the two partners was forced. That is, they were instructed to discuss topics of a personal nature, which is drastically different from engaging in a spontaneous conversation about a personal issue. Second, as previously mentioned, discussing a personal topic may not be the same as disclosing emotions and feelings. For example, revealing health problems is 
an intimate topic, but one can disclose information about this topic with or without feeling (Morton, 1978). In contrast, it is difficult to disclose how one is feeling without demonstrating emotional expressiveness. Unfortunately, coder reliability for emotional expressiveness was too low to assess in the current thesis.

Again, it is important to note that the self-reported depth measure incorporated aspects of both breadth and depth of the disclosure (the report of how much participants disclosed and how much they expressed their emotions) in the lab, whereas the Emotional Self-Disclosure Scale (Snell et al., 1988) solely focuses on depth. Thus, it might be that having one's partner disclose information is more important for satisfaction than disclosing information oneself, but being able to express one's emotions to one's partner in general is more important than having one's partner express emotions to oneself.

As previously mentioned, the Emotional Self-Disclosure Scale (Snell et al., 1988) asks participants to assess how much they express their emotions to their partner across time and situations (as opposed to during one brief interaction). Thus, emotional disclosure can fit into the framework of a self-schema. For example, if people perceive themselves to be expressive people, they may overestimate how much they express their emotions to their partners. As with any self-report, this measure may not be accurate measure of actual emotional disclosure. However, when it comes to issues of communication and relationship satisfaction, it appears that people's perceptions of themselves and their partners in the context of their relationship is more important for happiness than is actual behavior.

At the interaction level, A's RII was negatively related to coders' ratings of B's depth, B's self-reported depth, and A's report of B's depth. In contrast, at the general 
level, A's RII was not related to B's report of his/her emotional disclosure. Again, it is possible that B's reported depth and B's emotional disclosure are two completely distinct constructs. However, another possibility is that over time and across situations, B does not perceive him/herself as disclosing his/her emotions as a function of A's RII. That is, as people aggregate over time how much they disclose to their partners, they may be biased by how much they perceive themselves as disclosing in general (e.g., to previous partners, friends, family members, etc.). Thus, it is possible that when participants responded to how the questions regarding their emotional disclosure, they were reporting who they thought they were as opposed to how they behave with their partners.

As with most research investigating romantic relationships, this study was correlational. Thus, it is difficult to understand the direction of the correlations or to infer causality. For instance, is A's satisfaction in the relationship causing him to disclose his emotions more to B, or is A satisfied in the relationship because he discloses his emotions in his relationship with B? Although it is impossible to pull these relationships apart at this time, it is the current investigator's perspective that one partner's RII causes him/her to disclose less about him/herself and to be less trusting of his/her partner. These variables, in turn, are likely to decrease intimacy in the relationship and therefore decrease both partners' relationship satisfaction. This is because both disclosing to others and having others disclose to oneself have both been found to be important variables in relationship satisfaction (Meeks et al., 1998; Sprecher, 1987).

In the context of Reis and Shaver's (1988) model of the development of intimacy, risk in intimacy can influence the development of intimacy at two separate points. The first is if $\mathrm{A}$ is the person who is high in risk in intimacy. If $\mathrm{A}$ perceives high risk in 
intimacy, then he/she is likely to bring his/her risk schema to bear on an interaction with his/her partner. The risk schema can, in turn, cause A to enact his/her avoidance tendencies, which would decrease the extent to which A discloses and expresses his/her thoughts and feelings to B. The second point is when an individual plays the role of responder in a situation. After someone discloses personal information or feelings, it is the other person's job to respond to the disclosure. In doing so, the responder brings his/her expectations and schemas to bear onto the interaction. Thus, a high-RII person may misinterpret the disclosure (e.g., perceive it negatively instead of positively) or may not respond to the disclosure in an appropriate fashion (e.g., he/she may appear unresponsive). When one's behavior is perceived as unresponsive, unsupportive, or uncaring, interactions are less likely to become intimate. High-RII people are likely to be seen as aloof and uncaring. They are also likely to interpret their partners as being aloof, unsupportive, and uncaring (Nezlek \& Pilkington, 1994). Thus, in this way, high-RII individuals are more likely than low-RII people to prevent the process of the development of intimacy with others.

The results found in the current study can also be explained in accordance with Altman and Taylor's (1973) social penetration theory. According to Altman and Taylor's theory, disclosure with a stranger begins at a superficial level. If this disclosure is rewarding and trust in one's disclosure partner begins to develop, then subsequent disclosures are likely to increase both in breadth and in depth. As demonstrated in this research, the more risk in intimacy one perceives, the less trust one has in one's partner. Therefore, it is possible that relationships that include at least one high-RII partner fail to increase their disclosures over time in terms of the depth component measured here. 
When people lack trust in their partners or feel that their partners do not trust them, they may feel less satisfied in the relationship. Another possibility is that the dissatisfaction stems directly from the failure to disclose relevant personal information or have one's partner disclose personal information.

Although the current investigation yielded the relationships that were expected, it was not free of problems to be resolved in subsequent studies. First of all, for some of the variables that were coded, rater reliability was problematic and these variables were not investigated further. For example, coders had difficulty agreeing on participants' emotional investment. Although emotional investment would have been useful in subsequent analyses to investigate the difference between depth and expressiveness, it was not a possibility. Another possibility was that the component of emotional investment was lost due to the quality of the videotape. At times, the volume of the conversation was too low for coders to hear or the participants failed to speak clearly during their conversation. Thus, aspects as "the intensity of emotion communicated on a topic," such as speech intonation and hesitations may have been lost. This made the task of rating the conversation for such aspects as emotional investment especially difficult for the coders.

The current study was also limited because the couples' conversations in the laboratory only lasted six minutes. Because the study took place in the psychology laboratory, participants may not have been as comfortable as they would have been in other environments. Although it was hoped that the participants would have acclimated to the lab setting during the two-minute impersonal conversation, this acclimation may not have been completed. In addition, it would have been useful to have videotaped the 
personal conversation for eight minutes and treated the first two minutes of the personal conversation segment as an adjustment time for switching from impersonal topics to personal topics. It also would have been useful to videotape the interaction in a more comfortable location, which may have helped participants relax and behave more naturally.

Another problem with the study was that participants may have had too much freedom in choosing the topic they wanted to discuss. In other words, they had the opportunity to keep the conversation superficial while in the laboratory if they wanted to. This could have prevented them from being intimate and emotionally invested during their conversation, when in fact they normally would be. Other paradigms have couples discuss a recent disagreement or conflict because it is a situation that requires them to communicate at an intimate level and express thoughts and feelings (e.g., Prager, 1989). Therefore, a person's failure to be intimate, expressive, or responsive would be easier to detect. However, this methodology was not used in the current study because the topic for investigation was intimate communication rather than conflict resolution. Discussing conflict may have yielded a broader range of intimate communication among the couples, but the purpose of the current study was to investigate normal, everyday communication as opposed to investigating how couples solve relationship problems together.

For purposes of the current thesis, models were proposed to explain the relationships among the variables of perceptions of risk in intimacy, intimate communication, and relationship satisfaction. The next step for further research is to test these models formally. For example, it would be useful to determine if risk in intimacy moderates the relationship between intimate communication and relationship satisfaction. 
In addition, it would be beneficial to make use of a daily diary study to determine if highRII people really do perceive themselves as being less intimate with their partners over time and across situations and to determine if their partners perceive them to be less intimate as well. In addition, the daily diary method could help determine whether personal disclosure or people's perceptions of their partner's disclosures is the more important factor for relationship satisfaction. By utilizing the diary technique, researchers would be able to investigate how risk in intimacy and intimate communication relate to relationship satisfaction on a daily basis and in various kinds of interactions not accounted for by brief, self-reports that are obtained in the lab. Finally, the diary technique would also enable the researcher to determine lagged effects of intimate communication (or lack thereof) on relationship satisfaction.

Although further research is needed to provide additional insight into how highRII people develop and maintain intimacy in their relationships, it is important to address the potential problems that appear to exist in the meantime. That is, it appears that the higher one partner's perception of risk in intimacy, the less satisfied both partners are in the relationship. It seems that couples are less satisfied with the relationship when a high-RII partner is involved because high-RII people have difficulty communicating with their partners at the intimate level that is necessary for relationship satisfaction. Fortunately, counseling techniques exist that facilitate intimacy through cognitive selfdisclosure (Waring, 1981). Thus, rather than assume that relationships that involve highRII partners are doomed to fail, these couples can improve their relationship satisfaction through couple counseling that attempts to enhance their communication skills, and in turn, the intimacy both partners experience. 


\section{References}

Altman, I., \& Taylor, D. A. (1973). Social Penetration: The development of interpersonal relationships. New York: Holt, Rinehart, \& Winston.

Archer, R. L., \& Berg, J. H. (1978). Disclosure reciprocity and its limits: A reactance analysis. Journal of Experimental Social Psychology, 14, 527-540.

Bartko, J. J. (1976). On various intraclass correlation reliability coefficients. Psychological Bulletin, 83, 762-765.

Baumeister, R. F., \& Leary, M. R. (1995). The need to belong: Desire for interpersonal attachments as a fundamental human motivation. Psychological Bulletin, 117, 497-529.

Berger, C. R. (1988). Uncertainty and information exchange in developing relationships. In S. Duck (Ed.), Handbook of personal relationships: Theory, research, and interventions (pp. 239-256). New York: John Wiley \& Sons.

Brunell, A. B. (2001). Perceptions of risk in intimacy and patterns of self-disclosure. Unpublished first year project, College of William \& Mary, Williamsburg.

Burgoon, J. K., \& Hale, J. L. (1987). Validation and measurement of the fundamental themes of relational communication. Communication Monographs, 54, 19-41.

Chaikin, A. L., \& Derlega, V. J. (1974a). Liking for the norm-breaker in self-disclosure. Journal of Personality, 42, 117-129.

Chaikin, A. L., \& Derlega, V. J. (1974b). Variables affecting the appropriateness of selfdisclosure. Journal of Consulting and Clinical Psychology, 42, 588-593.

Chelune, G. J. (1977). Disclosure flexibility and social-situational perceptions. Journal of Consulting and Clinical Psychology, 45, 1139-1143. 
Clark, M. S., \& Reis, H. T. (1988). Interpersonal processes in close relationships. In Rosenzweig, M. R., \& Porter, L. W. (Eds.), Annual review of psychology: Vol. 39. (pp. 609-672). Palo Alto: Annual Reviews, Inc.

Cozby, P. C. (1973). Self-disclosure: A literature review. Psychological Bulletin, 40, 292-297.

Daher, D. M., \& Banikiotes, P. G. (1976). Interpersonal attraction and rewarding aspects of disclosure content and level. Journal of Personality and Social Psychology, $33,492-496$.

Derlega, V. J., Wilson, M., \& Chaikin, A. L. (1976). Friendship and disclosure reciprocity. Journal of Personality and Social Psychology, 34, 578-587.

Dindia, K. (2000). Sex differences in self-disclosure, reciprocity of self-disclosure, and self-disclosure and liking: Three meta-analyses reviewed. In S. Petronio (Ed.), Balancing the secrets of private disclosures (pp. 21-35). Mahwah, NJ: Erlbaum.

Fitzpatrick, M. A. (1986). Marriage and verbal intimacy. In V. J. Derlega \& J. Berg (Eds.), Self-disclosure: Theory, research, and therapy (pp.131-154). New York: Plenum.

Gable, S. L., \& Reis, H. T. (2001). Appetitive and aversive social interaction. In J. Harvey \& A. Wenzel (Eds.), Close romantic relationships: Maintenance and enhancement (pp. 169-194). New Jersey: Lawrence Erlbaum Associates.

Gonzalez, R., \& Griffin, D. (2000). On the statistics of interdependence: Treating dyadic data with respect. In W. Ickes \& S. Duck (Eds.), The social psychology of personal relationships (pp.181-231). New York: John Wiley \& Sons Ltd. 
Guerrero, L. K. (1997). Nonverbal involvement across interactions with same-sex friends, opposite-sex friends, and romantic partners: Consistency or change? Journal of Social and Personal Relationships, 14, 31-58.

Hanley-Dunn, P., Maxwell, S. E., \& Santos, J. P. (1985). Interpretation of interpersonal interactions: The influence of loneliness. Personality and Social Psychology Bulletin, 11, 445-456.

Hatfield, E. (1984). The dangers of intimacy. In V. J. Derlega (Ed.), Communication, intimacy, and close relationships (pp. 207-220). Orlando: Academic Press.

Keelan, J. P. R., Dion, K. K., \& Dion, K. L. (1998). Attachment style and relationship satisfaction: Test of a self-disclosure explanation. Canadian Journal of Behavioural Science, 30, 24-35.

Laurencau, J., Barrett, L. F., \& Pietromonaco, P. R. (1998). Intimacy as an interpersonal process: The importance of self-disclosure, partner disclosure, and perceived partner responsiveness in interpersonal exchanges. Journal of Personality and Social Psychology, 74, 1238-1251.

Lippert, T., \& Prager, K. J. (2001). Daily experiences of intimacy: A study of couples. Personal Relationships, 8, 283-298.

McAdams, D. P. (1985). Motivation and friendship. In S. Duck \& D. Perlman (Eds.), Understanding personal relationships: An interdisciplinary approach (pp.85105). London: Sage.

McAdams, D. P., \& Vaillant, G. E. (1982). Intimacy motivation and psychosocial adjustment: A longitudinal study. Journal of Personality Assessment, 46, 586593. 
Mikulincer, M., \& Nachshon, O. (1991). Attachment styles and patterns of selfdisclosure. Journal of Personality and Social Psychology, 61, 321-331.

Meeks, B. S., Hendrick, S. S., \& Hendrick, C. (1998). Communication, love and relationship satisfaction. Journal of Social and Personal Relationships, 15, 755773.

Mehrabian, A., \& Ksionzky, S. (1974). A theory of affiliation. Lexington: Lexington Books.

Miller, L. C., \& Berg, J. H. (1984). Selectivity and urgency in interpersonal exchange. In V. J. Derlega (Ed.), Communication, intimacy, and close relationships (pp.161205). New York: Academic Press.

Miller, R. S., \& Lefcourt, H. M. (1982). Social intimacy: An important moderator of stressful life events. American Journal of Community Psychology, 11, 127-139.

Morton, T. U. (1978). Intimacy and reciprocity of exchange: A comparison of spouses and strangers. Journal of Personality and Social Psychology, 36, 72-81.

Murray, S. L., Holmes, J. G., \& Griffin, D. W. (2000). Self-esteem and the quest for felt security: How perceived regard regulates attachment processes. Journal of Personality and Social Psychology, 78, 478-498.

Murstein, B. I. (1974). Love, Sex, and Marriage Through the Ages. New York: Springer.

Nezlek, J. B., \& Pilkington, C. J. (1994). Perceptions of risk in intimacy and social participation. Personal Relationships, 1, 45-62.

Palen, L. (2001). Perceptions of risk in intimacy and positive illusions. Unpublished honor's thesis, College of William \& Mary, Williamsburg. 
Pilkington, C. J. (1995). Perceptions of risk in intimacy: Avoiding intimacy by limiting self-disclosures. Unpublished manuscript, College of William \& Mary.

Pilkington, C. J., \& Richardson, D. R. (1988). Perceptions of risk in intimacy. Journal of Social and Personal Relationships, 5, 503-508.

Pilkington, C. J., \& Woods, S. P. (1999). Risk in intimacy as a chronically accessible schema. Journal of Social and Personal Relationships, 16, 249-263.

Prager, K. J. (1989). Intimacy status and couple communication. Journal of Social and Personal Relationships, 6, 435-449.

Prager (1995). The psychology of intimacy. New York: Guilford.

Prager, K. J., \& Buhrmester, D. (1998). Intimacy and need fulfillment in couple relationships. Journal of Social and Personal Relationships, 15, 435-469.

Reis, H. T., \& Patrick, B. C. (1996). Attachment and intimacy: Component processes. In E.T. Higgins \& A. W. Kruglanski (Eds.), Social psychology: Handbook of basic principles (pp. 523- 563). New York: Guilford Press.

Reis, H. T., \& Shaver, P. (1988). Intimacy as an interpersonal process. In S. Duck (Ed.), Handbook of personal relationships: Theory, research, and interventions (pp. 239-256). New York: John Wiley \& Sons.

Rempel, J. K., Holmes, J. G., \& Zanna, M. P. (1985). Trust in close relationships. Journal of Personality and Social Psychology, 49, 95-112.

Ruben, Z., Hill, C. T., Peplau, L. A., \& Dunkel-Schetter, C. (1980). Self-disclosure in dating couples: Sex roles and the ethic of openness. Journal of Marriage and the Family, 305-317. 
Shaffer, D. R., Smith, J. E., \& Tomarelli, M. (1982). Self-monitoring as a determinant of self-disclosure reciprocity during the acquaintance process. Journal of Personality and Social Psychology, 43, 163-175.

Snell, W. E., Miller, R. S., \& Belk, S. S. (1988). Development of the emotional selfdisclosure scale. Sex Roles, 18, 59-73.

Sprecher, S. (1987). The effects of self-disclosure given and received on affection for an intimate partner and stability of the relationship. Journal of Social and Personal Relationships, 4, 115-127.

Specher, S., Metts, S., Burleson, B., Hatfield, E., \& Thompson, A. (1995). Domains of expressive interactions in intimate relationships: Associations with satisfaction and commitment. Family Relations, 44, 203-210.

Waring, E. M. (1981). Facilitating marital intimacy through self-disclosure. The American Journal of Family Therapy, 9, 33-42. 
Table 1a

Pairwise Correlations for A's RII, Coders' Ratings of A's and B's Depth, A's Perception of B's Warmth, and Relationship Satisfaction.

\begin{tabular}{|c|c|c|c|c|c|}
\hline & $\begin{array}{c}\text { Coders' } \\
\text { Rating of } \\
\text { A's Depth } \\
\end{array}$ & $\begin{array}{l}\text { Coder's } \\
\text { Rating of } \\
\text { B's Depth }\end{array}$ & $\begin{array}{l}\text { A's Report of } \\
\text { B's Warmth }\end{array}$ & $\begin{array}{c}\text { A's } \\
\text { Relationship } \\
\text { Satisfaction } \\
\end{array}$ & $\begin{array}{c}\text { B's } \\
\text { Relationship } \\
\text { Satisfaction }\end{array}$ \\
\hline A's RII & $\begin{array}{c}r_{x y \cdot c}=-.01 \\
p=.90\end{array}$ & $\begin{array}{c}r_{x y^{\prime} \cdot c}=-.15 \\
p<.05\end{array}$ & $\begin{array}{c}r_{x y \cdot c}=-.27 \\
p<.002\end{array}$ & $\begin{array}{c}r_{x y . c}=-.37 \\
p<.0001\end{array}$ & $\begin{array}{c}r_{x y^{\prime} \cdot c}=-.30 \\
p<.02\end{array}$ \\
\hline $\begin{array}{l}\text { Coders' } \\
\text { Rating of } \\
\text { A's Depth }\end{array}$ & & $\begin{array}{l}r_{x x^{\prime} \cdot c}=.83 \\
p<.0001\end{array}$ & $\begin{array}{c}r_{x y . c}=-.12 \\
p=.11\end{array}$ & $\begin{array}{c}r_{x y . c}=-.13 \\
p=.14\end{array}$ & $\begin{array}{c}r_{x y^{\prime} \cdot c}=-.09 \\
p=.22\end{array}$ \\
\hline $\begin{array}{l}\text { Coder's } \\
\text { Rating of } \\
\text { B's Depth }\end{array}$ & & - & $\begin{array}{c}r_{x y^{\prime} \cdot c}=-.05 \\
p=.31\end{array}$ & $\begin{array}{c}r_{x y^{\prime} \cdot c}=-.09 \\
p=.22\end{array}$ & $\begin{array}{c}r_{x y . c}=-.13 \\
p=.14\end{array}$ \\
\hline $\begin{array}{c}\text { A's Report } \\
\text { of B's } \\
\text { Warmth }\end{array}$ & & & 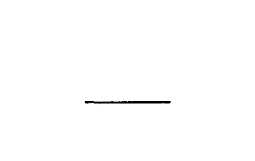 & $\begin{array}{l}r_{x y . c}=.41 \\
p<.0001\end{array}$ & $\begin{array}{c}r_{x y^{\prime} \cdot c}=.22 \\
p<.02\end{array}$ \\
\hline $\begin{array}{c}\text { A's } \\
\text { Relationship } \\
\text { Satisfaction }\end{array}$ & & & 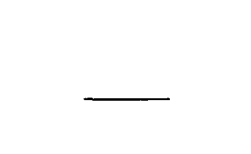 & 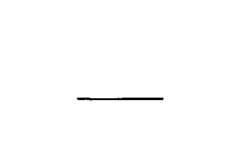 & $\begin{array}{l}r_{x x} \cdot c=.47 \\
p<.0002\end{array}$ \\
\hline
\end{tabular}


Table 1b

Pairwise Correlations for A's RII, Coders' Ratings of A's and B's Depth, A's Perception of B's Warmth, and Relationship Satisfaction.

\begin{tabular}{|c|c|c|c|c|c|}
\hline & $\begin{array}{c}\text { A's } \\
\text { Self- } \\
\text { Reported } \\
\text { Depth } \\
\end{array}$ & $\begin{array}{c}\text { B's } \\
\text { Self- } \\
\text { Reported } \\
\text { Depth } \\
\end{array}$ & $\begin{array}{l}\text { A's Report of } \\
\text { B's Warmth }\end{array}$ & $\begin{array}{c}\text { A's } \\
\text { Relationship } \\
\text { Satisfaction }\end{array}$ & $\begin{array}{l}\text { B's } \\
\text { Relationship } \\
\text { Satisfaction }\end{array}$ \\
\hline A's RII & $\begin{array}{c}r_{x y . c}=-.27 \\
p<.002\end{array}$ & $\begin{array}{c}r_{x y^{\prime} \cdot c}=-.23 \\
p<.007\end{array}$ & $\begin{array}{c}r_{x y . c}=-.27 \\
p<.002\end{array}$ & $\begin{array}{l}r_{x y . c}=-.37 \\
p<.0001\end{array}$ & $\begin{array}{c}r_{x y^{\prime} \cdot c}=-.30 \\
p<.02\end{array}$ \\
\hline $\begin{array}{c}\text { A's } \\
\text { Self- } \\
\text { Reported } \\
\text { Depth }\end{array}$ & - & $\begin{array}{c}r_{x x^{\prime} \cdot c}=.27 \\
p<.002\end{array}$ & $\begin{array}{l}r_{x y . c}=.41 \\
p<.0001\end{array}$ & $\begin{array}{c}r_{x y . c}=.12 \\
p=.11\end{array}$ & $\begin{array}{c}r_{x y^{\prime} \cdot c}=.06 \\
p=.27\end{array}$ \\
\hline $\begin{array}{c}\text { B's } \\
\text { Self- } \\
\text { Reported } \\
\text { Depth }\end{array}$ & & L & $\begin{array}{c}r_{x y^{\prime} \cdot c}=.22 \\
p<.01\end{array}$ & $\begin{array}{c}r_{x y^{\prime} \cdot c}=.06 \\
p=.27\end{array}$ & $\begin{array}{c}r_{x y . c}=.12 \\
p=.11\end{array}$ \\
\hline $\begin{array}{c}\text { A's Report } \\
\text { of B's } \\
\text { Warmth }\end{array}$ & & - & 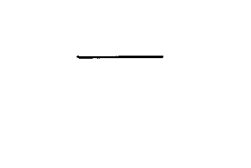 & $\begin{array}{l}r_{x y . c}=.41 \\
p<.0001\end{array}$ & $\begin{array}{c}r_{x y^{\prime} \cdot c}=.22 \\
p<.02\end{array}$ \\
\hline $\begin{array}{c}\text { A's } \\
\text { Relationship } \\
\text { Satisfaction }\end{array}$ & & - & 工 & - & $\begin{array}{l}r_{x x^{\prime} \cdot c}=.47 \\
p<.0002\end{array}$ \\
\hline
\end{tabular}


Table 1c

Pairwise Correlations for A's RII, A's Perception of B's Depth, B's Perception of A's

Depth, A's Perception of B's Warmth, and Relationship Satisfaction.

\begin{tabular}{c|ccccc}
\hline & $\begin{array}{c}\text { A's } \\
\text { Report of } \\
\text { B's Depth }\end{array}$ & $\begin{array}{c}\text { B's Report } \\
\text { of A's Depth }\end{array}$ & $\begin{array}{c}\text { A's Report } \\
\text { of B's } \\
\text { Warmth }\end{array}$ & $\begin{array}{c}\text { A's } \\
\text { Relationship } \\
\text { Satisfaction }\end{array}$ & $\begin{array}{c}\text { B's } \\
\text { Relationship } \\
\text { Satisfaction }\end{array}$ \\
\hline A's RII & $\begin{array}{c}r_{x y . c}=-.20 \\
p<.01\end{array}$ & $\begin{array}{c}r_{x y^{\prime} \cdot c}=.15 \\
p=.05\end{array}$ & $\begin{array}{c}r_{x y \cdot c}=-.27 \\
p<.002\end{array}$ & $\begin{array}{c}r_{x y . c}=-.37 \\
p<.0001\end{array}$ & $\begin{array}{c}r_{x y^{\prime} \cdot c}=-.30 \\
p<.02\end{array}$ \\
A's Report \\
of B's Depth
\end{tabular}


Table 2

Pairwise Correlations with A's Emotional Self-Disclosure

\begin{tabular}{l|ccccc}
\hline & $\begin{array}{c}\text { Coders' } \\
\text { Rating of } \\
\text { A's Depth }\end{array}$ & $\begin{array}{c}\text { A's Self- } \\
\text { Reported } \\
\text { Depth }\end{array}$ & A's RII & $\begin{array}{c}\text { A's } \\
\text { Relationship } \\
\text { Satisfaction }\end{array}$ & $\begin{array}{c}\text { B's } \\
\text { Relationship } \\
\text { Satisfaction }\end{array}$ \\
\hline A's & & & & & \\
Emotional & $r_{x y . c}=-.09$ & $r_{x y . c}=.32$ & $r_{x y . c}=-.41$ & $r_{x y . c}=.39$ & $r_{x y^{\prime} \cdot c}=.22$ \\
Self- & $p=.18$ & $p<.002$ & $p<.0001$ & $p<.0001$ & $p<.001$ \\
Disclosure & & & & & \\
& & & & & \\
\hline
\end{tabular}


Table 3

Pairwise Correlations with A's Trust

\begin{tabular}{c|cccc}
\hline & A's RII & $\begin{array}{c}\text { A's Emotional } \\
\text { Self-Disclosure }\end{array}$ & $\begin{array}{c}\text { A's } \\
\text { Satisfaction }\end{array}$ & $\begin{array}{c}\text { B's } \\
\text { Satisfaction }\end{array}$ \\
\hline \multirow{3}{*}{ A's Trust } & & & & \\
& $r_{x y . c}=-.34$ & $r_{x y . c}=.49$ & $r_{x y . c}=.56$ & $r_{x y^{\prime} . c}=.44$ \\
& $p<.0002$ & $p<.0001$ & $p<.0001$ & $p<.0001$ \\
\hline
\end{tabular}


Figure 1

Triangulation of A's Behavior.

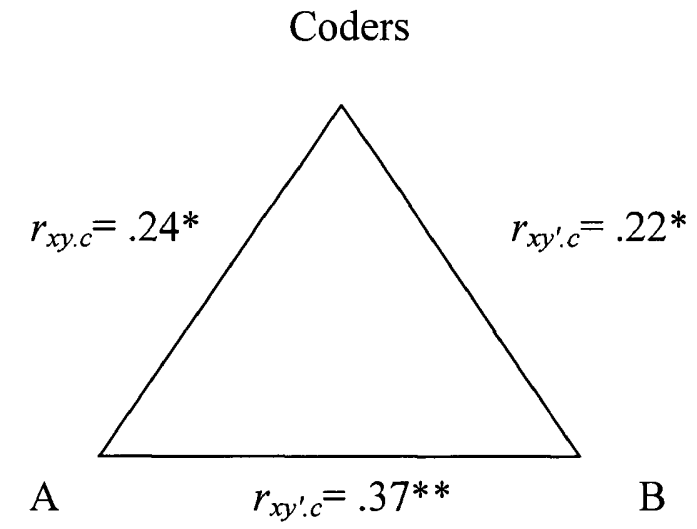

Note: $* p<.05, * * p<.01$ 
Figure 2

Evaluation of A's RII and A's Intimate Behavior.

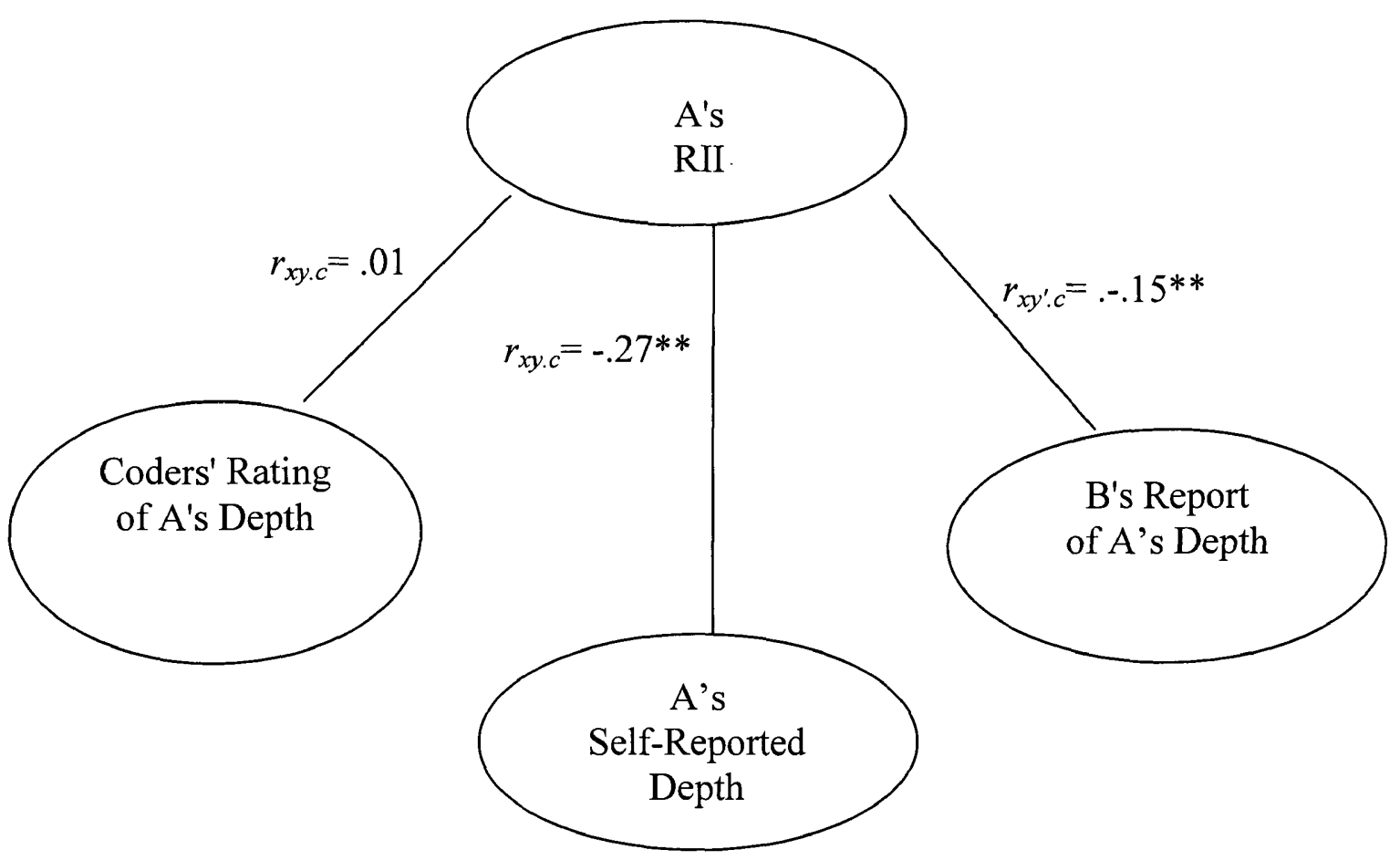

Note: ${ }^{*} p<.001$ 


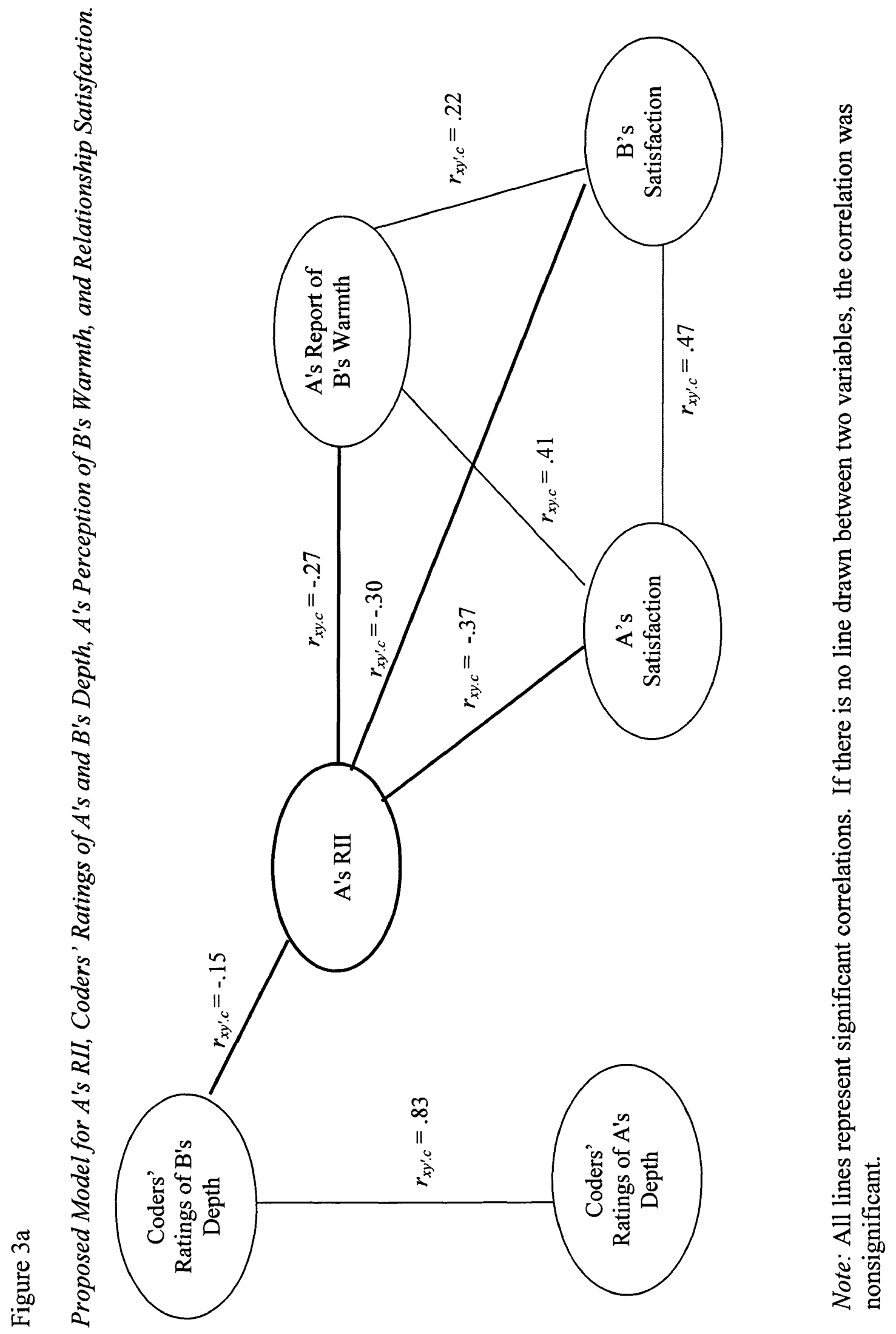




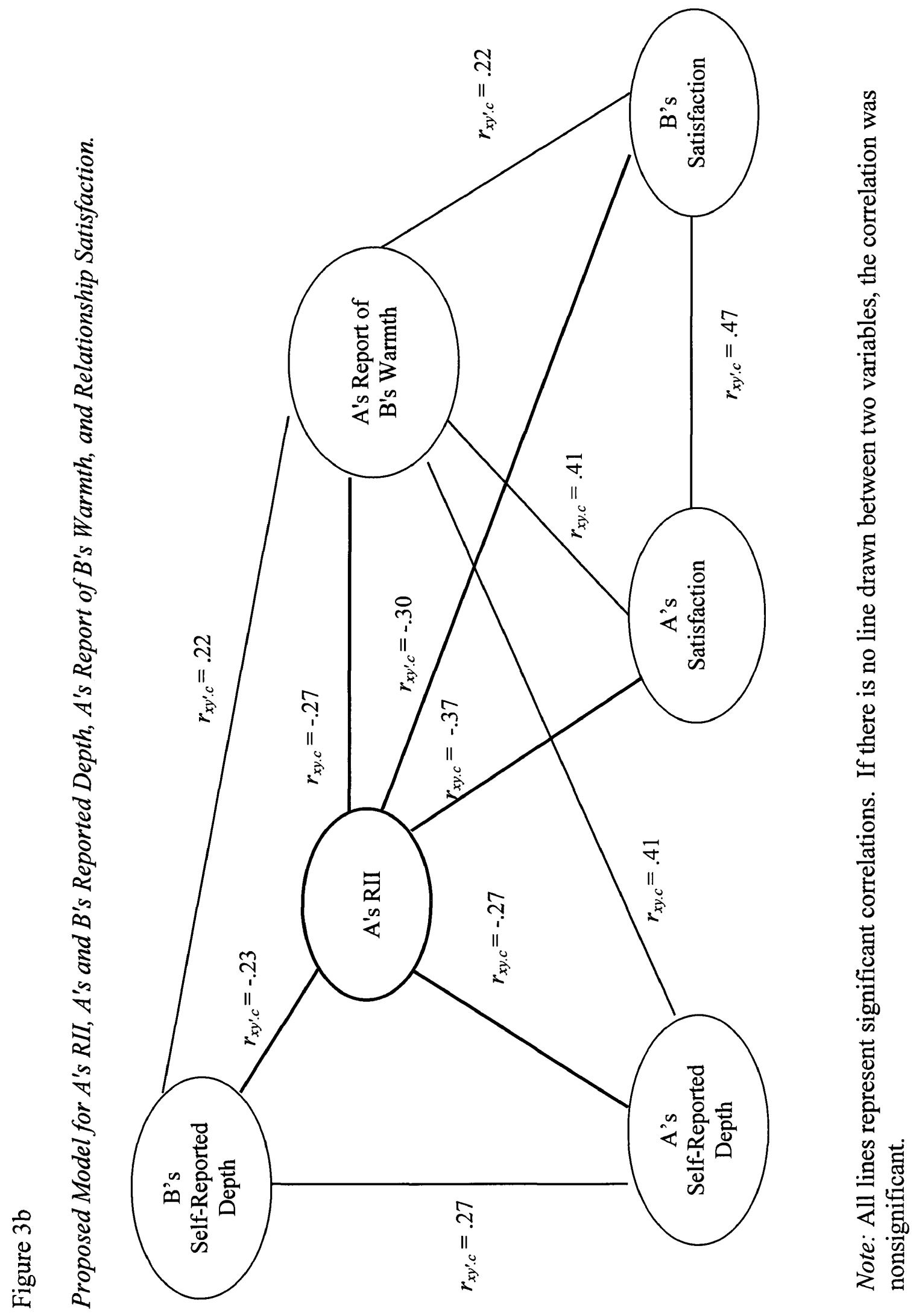




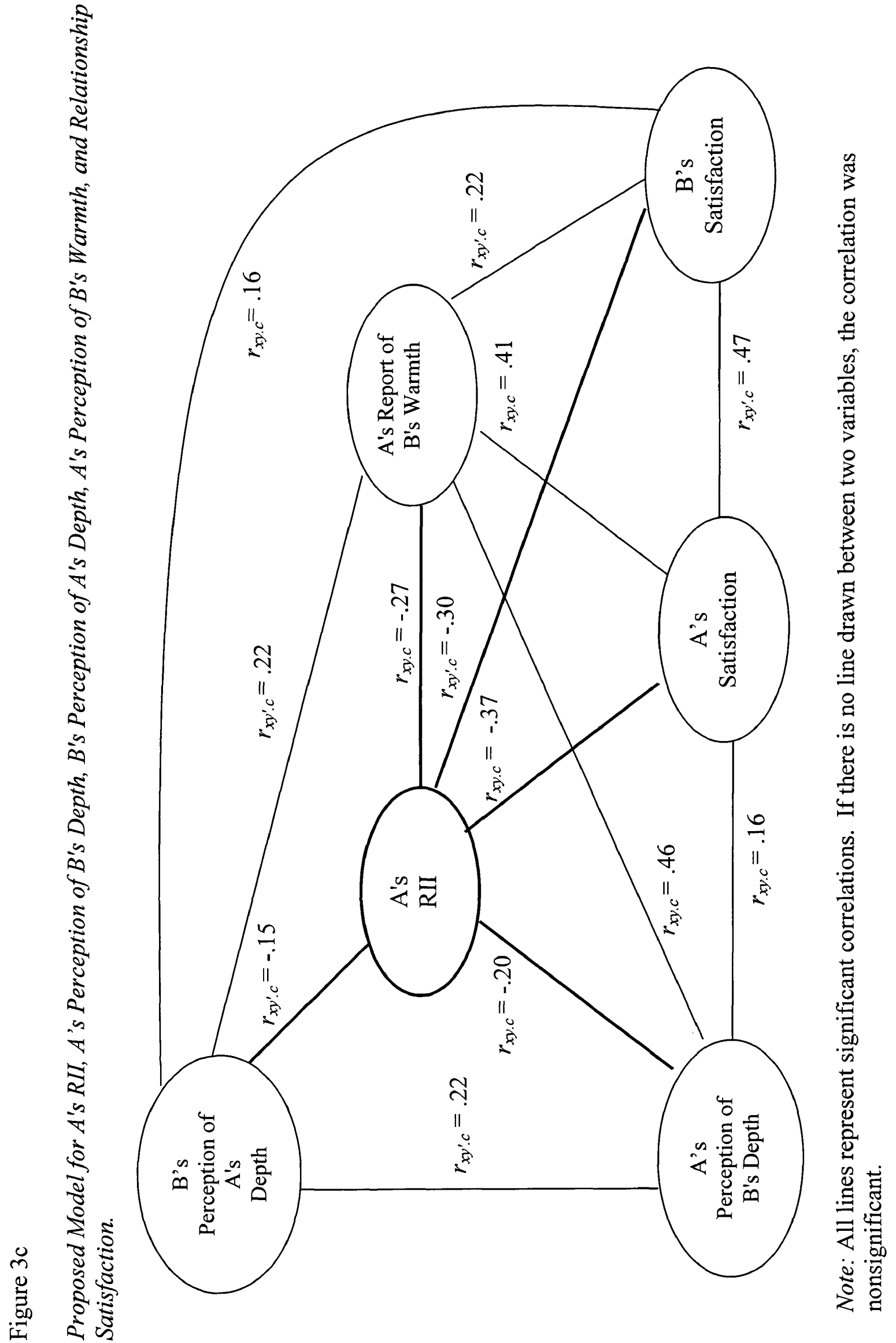




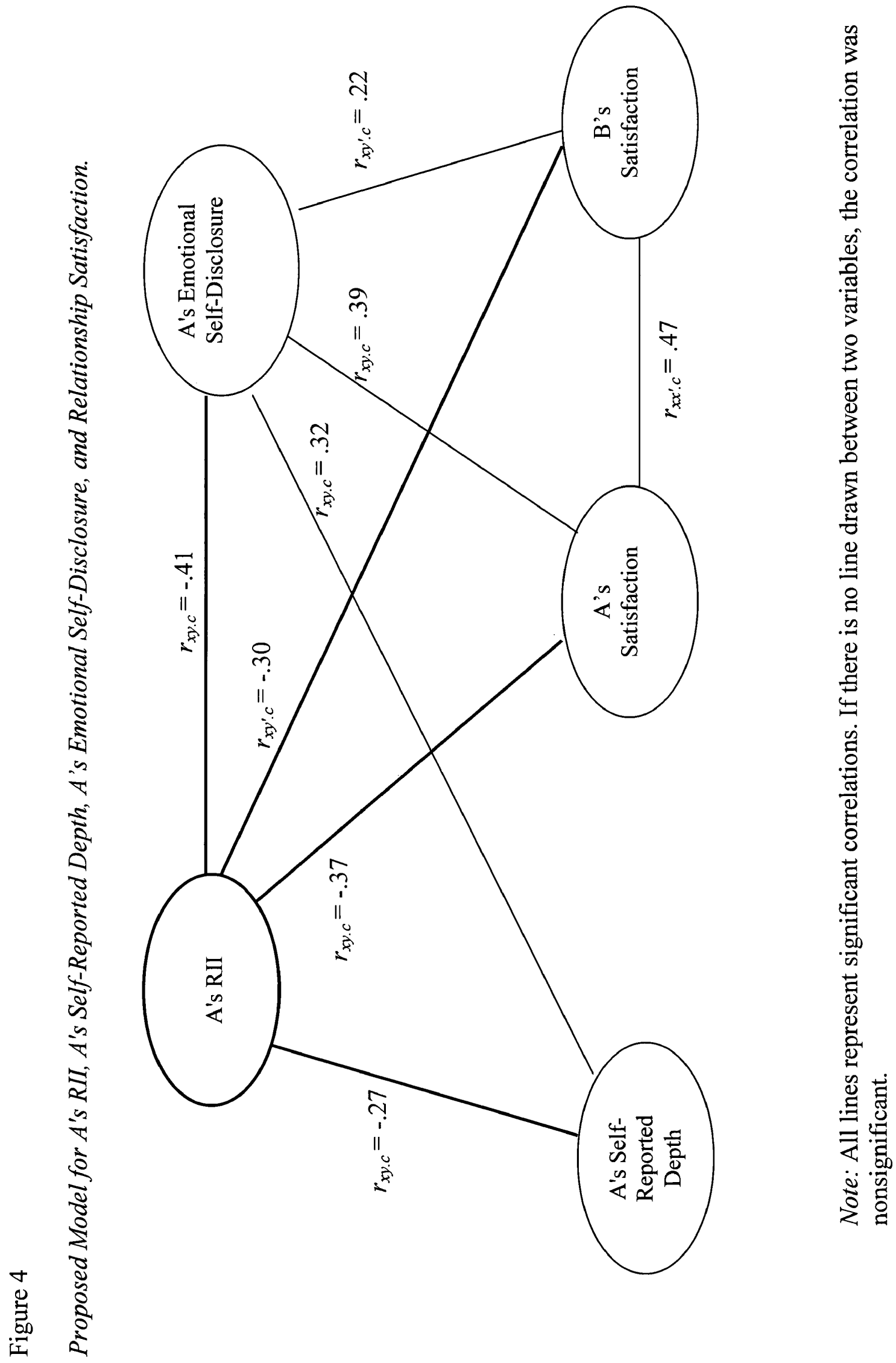




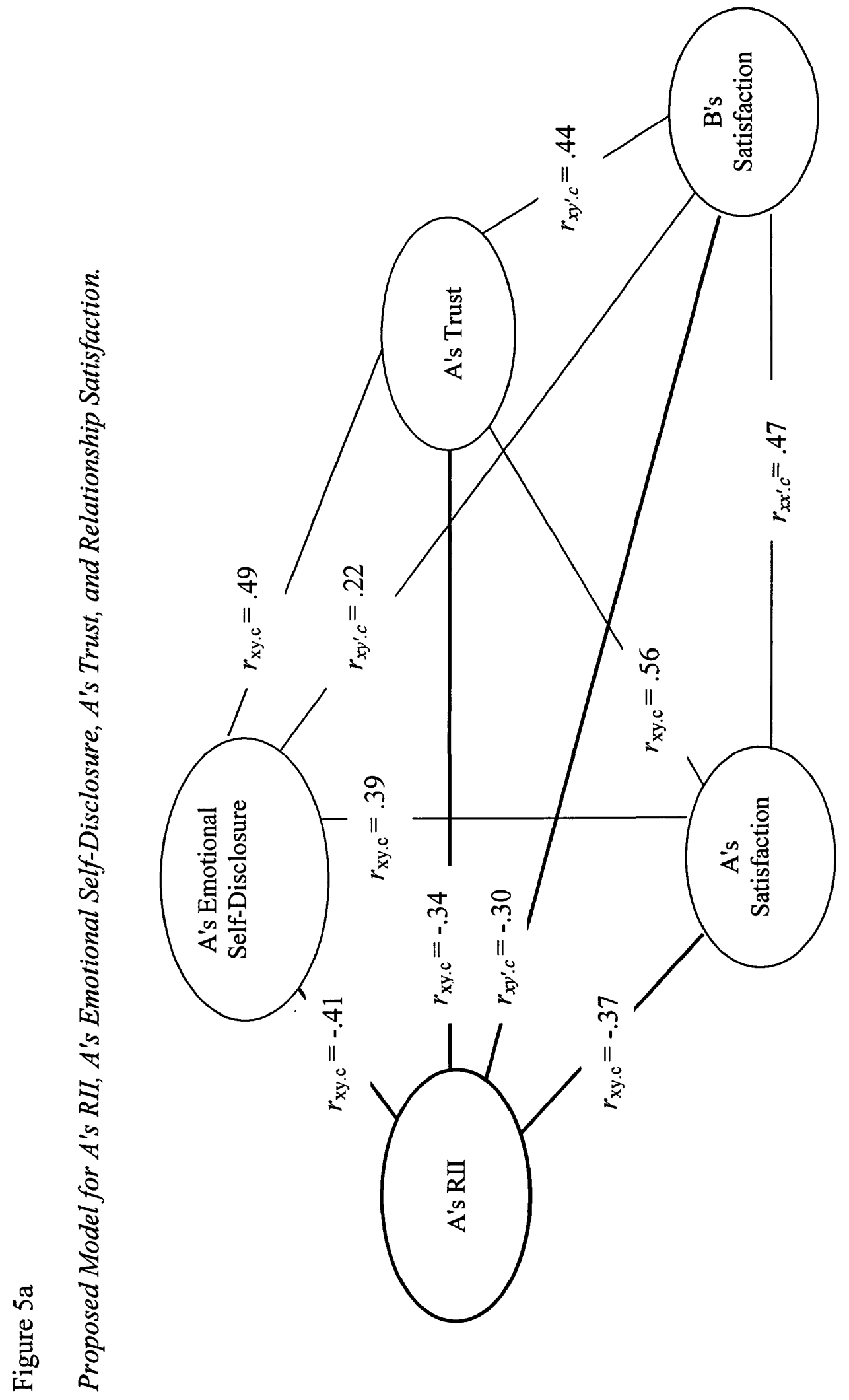

: 


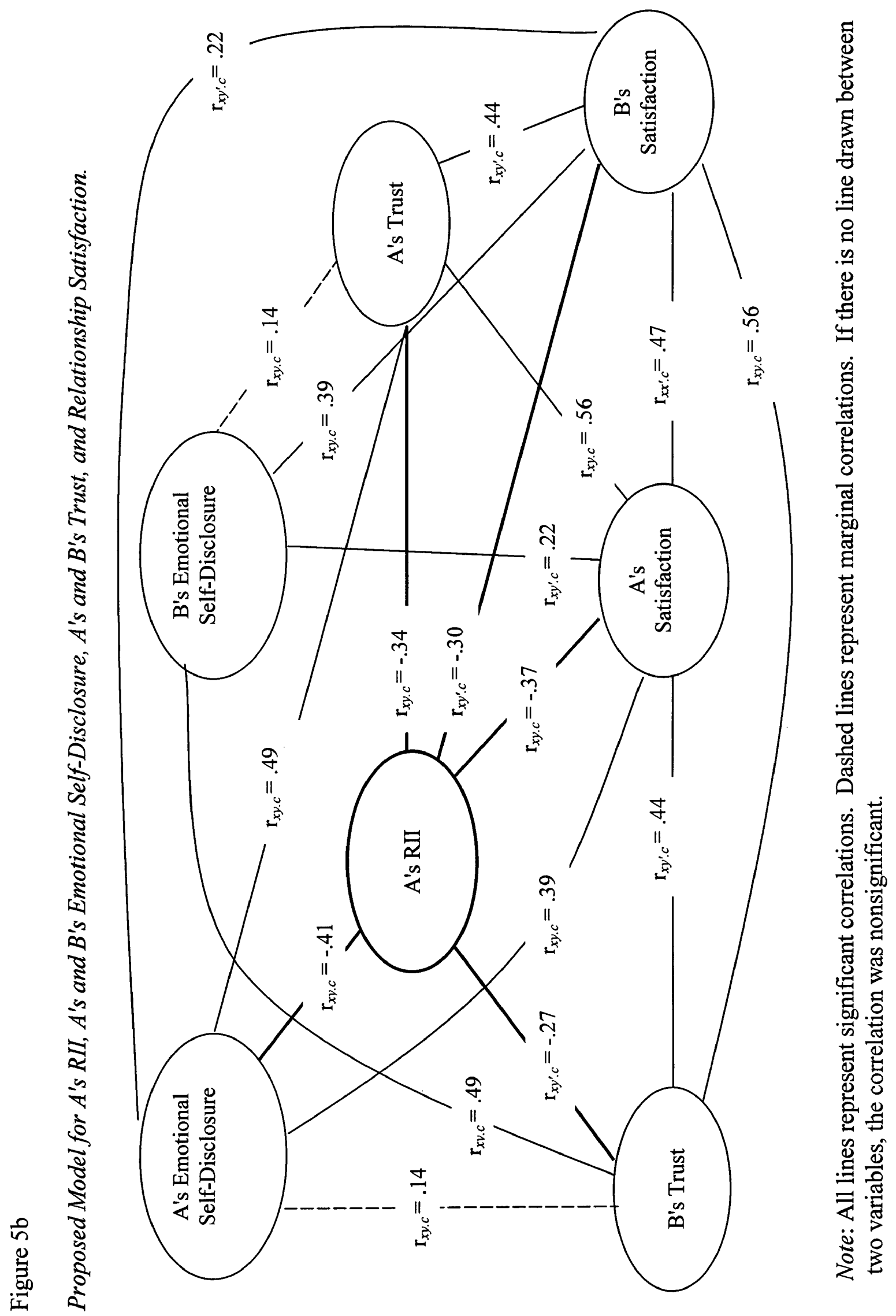


Appendix A

Pilkington \& Richardson (1988) Risk in Intimacy Inventory

Listed below are several statements that reflect different attitudes about relationships. Some of the items refer to general attitudes or beliefs about relationships. Other items refer to more specific kinds of interactions, such as those with acquaintances (e.g., someone you've met only once, someone you know only from class), with casual friends, or with people you are very close to.

Using the scale below, indicate the extent to which you agree with each statement by writing the appropriate number in the blank beside each item.

$$
\begin{array}{ll}
1=\text { very strong disagreement } & 4=\text { slight agreement } \\
2=\text { moderate disagreement } & 5=\text { moderate agreement } \\
3=\text { slight disagreement } & 6=\text { very strong agreement }
\end{array}
$$

There are no right or wrong answers. This is simply a measure of how you feel. Please try to give an honest appraisal of yourself.

1. It is dangerous to get really close to people.

2. I prefer that people keep their distance from me.

3. I'm afraid to get really close to someone because I might get hurt.

4. At best, I can handle only one or two close friendships at a time.

5. I find it difficult to trust other people.

6. I avoid intimacy.

7. Being close to other people makes me feel afraid.

8. I'm hesitant to share personal information about myself.

9. Being close to people is a risky business.

10. The most important thing to consider in a relationship is whether I might get hurt. 
Appendix B

Rempel, Holmes, \& Zanna (1985) Interpersonal Trust Scale

\begin{tabular}{|c|c|c|c|c|c|c|c|}
\hline & $\begin{array}{l}\text { Strongly } \\
\text { Disagree }\end{array}$ & & & & & & $\begin{array}{c}\text { Strongly } \\
\text { Agree }\end{array}$ \\
\hline $\begin{array}{l}1 \text { My partner has proven to be } \\
\text { trustworthy and I am willing to } \\
\text { let him/her engage in activities } \\
\text { which other partners might find } \\
\text { too threatening. }\end{array}$ & 1 & 2 & 3 & 4 & 5 & 6 & 7 \\
\hline $\begin{array}{l}2 \text { Even when I don't know how } \\
\text { my partner will react, I feel } \\
\text { comfortable telling him/her } \\
\text { things of which I am ashamed. }\end{array}$ & 1 & 2 & 3 & 4 & 5 & 6 & 7 \\
\hline $\begin{array}{l}3 \text { Though times may change and } \\
\text { the future is uncertain, I know } \\
\text { my partner will always be ready } \\
\text { and willing to offer me strength } \\
\text { and support. }\end{array}$ & 1 & 2 & 3 & 4 & 5 & 6 & 7 \\
\hline $\begin{array}{l}4 \text { I am never certain that my } \\
\text { partner won't do something that } \\
\text { I dislike or will embarrass me. }\end{array}$ & 1 & 2 & 3 & 4 & 5 & 6 & 7 \\
\hline $\begin{array}{l}5 \text { My partner is very } \\
\text { unpredictable. I never know } \\
\text { how he/she is going to act from } \\
\text { one day to the next. }\end{array}$ & 1 & 2 & 3 & 4 & 5 & 6 & 7 \\
\hline $\begin{array}{l}6 \text { I feel very uncomfortable when } \\
\text { my partner makes decisions that } \\
\text { will affect me personally. }\end{array}$ & 1 & 2 & 3 & 4 & 5 & 6 & 7 \\
\hline $\begin{array}{l}7 \text { I have found that my partner is } \\
\text { unusually dependable, } \\
\text { especially when it comes to } \\
\text { things that are important to me. }\end{array}$ & 1 & 2 & 3 & 4 & 5 & 6 & 7 \\
\hline
\end{tabular}

$8 \mathrm{My}$ partner behaves in a very consistent manner.

9 Whenever we have to make an 
Appendix B, continued

Rempel, Holmes, \& Zanna (1985) Interpersonal Trust Scale

10 Even if I have not reason to

Strongly

Strongly

Disagree

expect my partner to share things with me, I feel certain that he/she will.

11 I can rely on my partner to react in a positive way when I expose my weaknesses to him/her.

12 When I share my problems with my partner, I know he/she will respond in a loving way even before I say anything.

13 I am certain that my partner would not cheat on me, even if the opportunity arose and there was no chance that he/she would get caught.

14 I sometimes avoid my partner 1 2

3
4 Agree

7 because he/she is unpredictable and I fear saying or doing something that might create conflict.

15 I can rely on my partner to keep promises that he/she makes to me.

16 When I am with my partner I new situations.

17 Even when my partner makes excuses that sound rather unlikely, I am confident that he/she is telling the truth. 
Appendix C

Romantic Relationship Satisfaction Inventory

Circle the response that most closely describes your feelings about each statement.

I am extremely happy with $\quad 1$ Disagree

\section{Strongly}

our relationship.

2 I have a very strong relationship with my partner.

3 I do not feel that my current relationship is successful.

4 My relationship with my partner is very rewarding.

5 I often think about ending my current relationship.

$6 \mathrm{My}$ relationship is close to my ideal.

7 I do not like my partner.

$8 \mathrm{I}$ am in love with my partner.

9 In general, I often think that things between my partner and I are going well.

10 I often regret becoming involved in my current relationship.

11 I am satisfied with my relationship.

12 I am not very serious about my current relationship.

13 I consider myself committed to my current relationship. 
Appendix D

Snell, Miller, \& Belk (1988) Emotional Self-Disclosure Scale

Please use the following scales to indicate how willing you would be to discuss each topic with your romantic partner.

\section{Not at all \\ willing to \\ discuss \\ this topic}

Totally willing to discuss

1 Times when you felt depressed

2 Times when you felt happy

3 Times when you felt jealous

4 Times when you felt anxious

5 Times when you felt angry

6 Times when you felt calm

7 Times when you felt apathetic

8 Times when you felt afraid

1
1
1
1
1
1
1
1
1

this topic

9 Times when you felt discouraged

10 Times when you felt cheerful

11 Times when you felt possessive

12 Times when you felt troubled

13 Times when you felt infuriated

14 Times when you felt quiet

15 Times when you felt indifferent

16 Times when you felt fearful

17 Times when you felt pessimistic

18 Times when you felt joyous

19 Times when you felt envious

20 Times when you felt worried

21 Times when you felt irritated

22 Times when you felt serene

23 Times when you felt numb

24 Times when you felt frightened

25 Times when you felt sad

26 Times when you felt delighted

27 Times when you felt suspicious

28 Times when you felt uneasy

29 Times when you felt hostile

30 Times when you felt tranquil

31 Times when you felt unfeeling

2
2
2
2
2
2
2
2
2

\section{3}

3

\section{3}

3

\section{3}

3

\section{3}

3

3

\section{4}

4

5

5

5

5 
Appendix D continued

Snell, Miller, \& Belk (1988) Emotional Self-Disclosure Scale

32 Times when you felt scared

33 Times when you felt unhappy

34 Times when you felt pleased

35 Times when you felt resentful

36 Times when you felt flustered

37 Times when you felt enraged

38 Times when you felt relaxed

39 Times when you felt detached

40 Times when you felt alarmed
Not at all

willing to

discuss

this topic

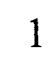

1

1

1

1

1

1

1

1

1
1
1
1
1
1
1
1
1

Totally willing to discuss this topic 5 5 5 5 5 5 5 5 5 
Appendix E

Post-Conversation Questionnaire

Think about the conversation you just had with your romantic partner. Keeping this conversation in mind, please answer the following questions using the scale below.

Not at all/

Not much

$$
\begin{aligned}
& \text { Very/ } \\
& \text { Very } \\
& \begin{array}{llllllll}
1 & 2 & 3 & 4 & 5 & 6 & 7
\end{array}
\end{aligned}
$$

1. How much did you disclose to your partner during your conversation?

2. How much did you express your emotions during your conversation?

3. How much did your partner disclose to you during your conversation?

4. How much did your partner express emotions during your conversation?

5. How accepted did you feel by your partner during your conversation?

6 . How close did you feel to your partner during your conversation?

7. How understood did you feel by your partner?

8. How much did you feel cared for by your partner during your conversation?

9. Indicate, in terms of percent, how much of what you said during the conversation was about:

Facts $\%$
Thoughts_ $\%$
Feelings_ $\%$
Other $\%$

Total $100 \%$

10. Indicate, in terms of percent, how much of what your partner said during the conversation was about:

Facts $\%$
Thoughts $\%$
Feelings $\%$
Other $\%$

Total $100 \%$ 
VITA

$\underline{\text { Amy Beth Brunell }}$

The author was born in New Brunswick, New Jersey on June 8, 1978. She graduated from Ridgewood High School in Ridgewood, New Jersey in June of 1996. In May of 2000, she graduated with Honors and received her B.A. in Psychology from Muhlenberg College in Allentown, Pennsylvania. She received her M.A. in Psychology from the College of William and Mary in Williamsburg, Virginia in August of 2002.

In August of 2002, the author will be attending the University of Georgia as a Ph.D. candidate in the department of Social Psychology. 